JPL D-1429

SPAOO PROGRAM

Technical Information Report

\title{
Launch Vehicle Integration \\ Requirements for SP-100
}

L. Tom Shaw, Jr.

James R. Womack

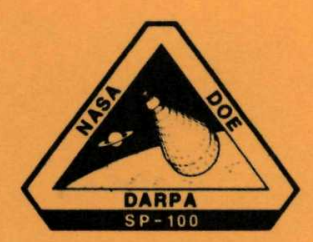

March 1984

National Aeronautics and

Space Administration

JPL

Jet Propulsion Laboratory

California Institute of Technology

Pasadena, California 


\section{DISCLAIMER}

This report was prepared as an account of work sponsored by an agency of the United States Government. Neither the United States Government nor any agency Thereof, nor any of their employees, makes any warranty, express or implied, or assumes any legal liability or responsibility for the accuracy, completeness, or usefulness of any information, apparatus, product, or process disclosed, or represents that its use would not infringe privately owned rights. Reference herein to any specific commercial product, process, or service by trade name, trademark, manufacturer, or otherwise does not necessarily constitute or imply its endorsement, recommendation, or favoring by the United States Government or any agency thereof. The views and opinions of authors expressed herein do not necessarily state or reflect those of the United States Government or any agency thereof. 


\section{DISCLAIMER}

Portions of this document may be illegible in electronic image products. Images are produced from the best available original document. 


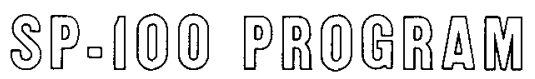

\title{
Technical Information Report
}

\section{Launch Vehicle Integration Requirements for SP-100}

\author{
L. Tom Shaw, Jr. \\ James R. Womack
}

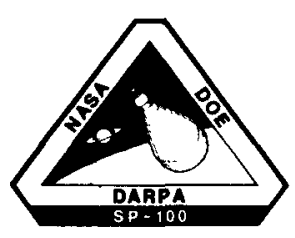

March 1984

National Aeronautics and

Space Administration

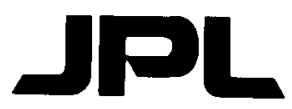

Jet Propulsion Laboratory

California Institute of Technology

Pasadena, California 


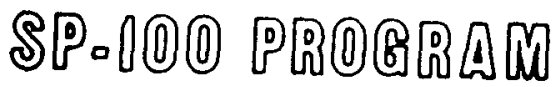

\author{
THIS REPORT IS INTENDED FOR USE ONLY BY THOSE AGENCIES AND GOVERNEMENT \\ ORGANIZATIONS WHICH HAVE RESPONSIBILITIES FOR EXECUTING PORTIONS OF THIS \\ PROJECT
}

\section{DISCLAIMER}

This report was prepared as an account of work sponsored by an agency of the United States Government. Neither the United States Government nor any agency thereof, nor any of their employees, makes any warranty, express or implied, or assumes any legal liability or responsibility for the accuracy, completeness, or usefulness of any information, apparatus, product, or process disclosed, or represents that its use would not infringe privately owned rights. Reference herein to any specific commercial product, process, or service by trade name, trademark, manufacturer, or otherwise does not necessarily constitute or imply its endorsement, recommendation, or favoring by the United States Government or any agency thereof. The views and opinions of authors expressed herein do not necessarily state or reflect those of the United States Government or any agency thereof.

\author{
Department of Defense \\ Defense Advanced Research Projects Agency \\ Arlington, Virginia \\ Department of Energy \\ Office of Nuclear Energy \\ Washinglon, D.C. \\ National Aeronautics and Space Administration \\ Office of Aeronautics and Space Technology \\ Wastington, D.C. \\ Jel Propulsion Laboratory \\ California Institute of Technology \\ Pasadena. Calitornia
}


CUNIENTS

1. INTRODUCTIUN ....................... . . 1-1

2. NSTS UVERVIEW AND TEKMINULUGY . . . . . . . . . . . . . . . . 2-1

2.1 NSTS DLFINITION AND TEKMINOLOGY . . . . . . . . . . 2 2-1

2.2 GKOUND AND FLIGHT OPERATIUNS SCENAKIO . . . . . . . . . 2-1

2.2.1 Pre-Launch (Launch Site Operations) . . . . . 2-2

2.2.2 Ascent ................... $2-2$

2.2.3 On-Orbit Operations ............. 2-2

2.2.4 Detached Phase ............... 2-3

2.3 SSV PERfURMANCE CAPABILITY . . . . . . . . . . . 2 .

2.4 SSV/UPPEK STAGE PEKFOKMANCE ESTIMATES . . . . . . . . . Z 24

3. NSTS/PAYLOAD INTEGKATION PKOCESS . . . . . . . . . . . . . . . j-1

j.1 PROJECT/NSTS INTEKFACING ANL PLANNING . . . . . . . . . . 3-1

3.2 INTEGRATION/INTEkFACE WUKKING GKOUPS . . . . . . . . . 3-2

3.3 NSTS/KSC OPERATIUNS/INIEKFACE YLANNING . . . . . . . . . 3-2

3.4 SAFEIY KEVIEWS ....................... $3-2$

3.5 NSTS/KSC MAJOR REVIEWS . . . . . . . . . . . . . 3-3

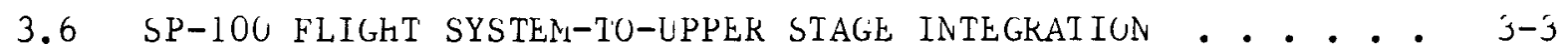

4. SPACE SHUTTLE-TO-PAYLOAD INTERFACE CHAKACTERISTICS . • • • • . . 4-1

4.1 PHYSICAL INTEKFACE . . . . . . . . . . . . . . . 4-1

4.1.1 Coordinate Reference Axis . . . . . . . . . 4-1

4.1.2 Allowable Thermal and Dynamic Envelope ...... 4-1

4.1.3 Interface Locations and Attachments ........ 4-1

4.2 STKUCTURAL INTEKFACES . . . . . . . . . . . . . 4-3

4.3 FlUIL INTERFACES . . . . . . . . . . . . . 4-3 
CUNTENTS (continued)

4.4 ENVIRONMENTAL CONTROL INTERFACES . . . . . . . . . . . 4-3

4.5 ELECTKICAL POWER INTERHACE ................ . 4-4

4.6 AVIONICS INTERFACES .................... . . $4-4$

4.7 ENVIRONMENTAL KEQUIREMENTS . . . . . . . . . . . . . 4-4

4.8 OTHER INTERFACES . . . . . . . . . . . . . . . . 4-4

5. INTERFACE CHAKACTERISTICS AND KEQUIKEMENTS OF NSTS UPPEK SIAGES • 5-1

5.1 CENTAUK ........................ . . . . . . .

5.1.1 Structural/Mechanical Interfaces . . . . . . 5-1

5.1.2 Thermal Interfaces ............. 5-5

5.1.3 Fluid Interfaces . . . . . . . . . . 5-5

5.1.4 Avionics and Electrical Power Interfaces .... . 5-5

5.1.5 Centaur Environmental Interfaces . . . . . . . 5-6

5.2 TRANSFER URBIT STAGE (TOS) . . . . . . . . . . . . 5-6

5.2.1 Structural/Mechanical Interfaces . . . . . . 5-6

5.2.2 Thermal Interfaces ............. . 5-10

5.2.3 Fluid Interfaces . . . . . . . . . . . 5-10

5.2.4 Avionics and Electrical Interfaces . . . . . . b-13

5.2.5 TUS Letached Phase Environmental Interfaces . . . . 5-13

5.3 INEkTIAL UPPEK STAGE . . . . . . . . . . . . 5-1's

5.3.1 Structural/Mechanical Interfaces . . . . . . 5-15

5.3.2 Thermal Interfaces ............. . . 5-15

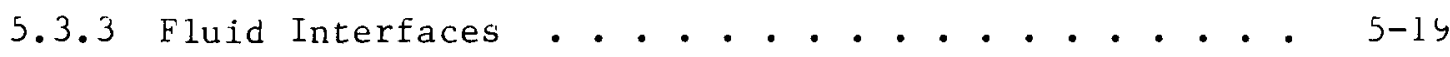

5.3.4 Avionics and Electrical Intertaces . . . . . . 5-1s

5.3.5 Environmental Interfaces . . . . . . . . 5-22 
CONlENIS (Continued)

6. PAYLUAL/NSIS INTLKFACE VLKIFICATION . . . . . . . . . . 6-1

7. KLFERENCE DUCUMENTS .................... . . . $7-1$

\section{Figures}

2-1. Near-Term Cargo Weight Versus Circular Orbital Altitude KSC Launch, Lelivery Unly . . . . . . . . . . 2-3

2-2. Centaur G Performance: Payload Versus Velocity . . . . . 2-5

2-3. Centaur G Performance: Yayload Versus Altitude, Circular Orbit... . . . . . . . . . . . $2-5$

2-4. Centaur $G^{\prime}$ Performance . . . . . . . . . . . 2-6

2-5. Centaur G' Performance: Payload Versus Altitude, Circular Orbit . . . . . . . . . . . . . . $z-6$

2-6. TOS Ferformance: Payload Versus Velocity . . . . . . . ¿-7

2-7. TOS Performance: Payload Versus Altitude, Transfer Orbit . 2-7

2-8. TuS Performance, Circularization $\Delta V . . . . . . . .4-\delta$

2-9. TOS Velocity, Capability Versus Payload, both Sides Fully Loaded .................... . . $2-\delta$

2-10. IUS Performance, Payload Versus Velocity, Circular Orbit . . ¿-y

2-11. IUs Performance: Payload Versus Altitude, Circular Orbit . 2-10

4-1. SSV Orbiter Payload Coordinate System (Mechanical).... 4-2

5-1. Centaur G Configuration ............ . S-2

5-2. Centaur $G^{\prime}$ Configuration . . . . . . . . . . 5-3

5-3. Preliminary Design Limit Loads . . . . . . . . . . 5-4

5-4. Telemetry and Command Functional Interfaces with Centaur and Shuttle (Attached Phase) . . . . . . . . . 5-7

5-5. Telemetry and Command Functional Interfaces with Centaur (Detached Phase) . . . . . . . . . . . . 5-8 
CONIENTS (Continued)

\section{Figures}

5-6. Centaur Boost Acceleration . . . . . . . . . . . 5-y

5-7. Transfer Orbit Stage Configuration . . . . . . . . . S-s

5-8. Standard TOS/Spacecraft Interface .......... . 5-11

5-y. TOS Coordinate System ............... . 5-11

5-10. TOS/Spacecraft Installation in Orbiter bay . . . . . 5-lí

5-11. IUS Two-Stage Vehicle Outline . . . . . . . . . 5-14

5-12. IUS/SC Attachment Interface ............. 5-16

5-13. IUS Vehicle/ASt Coordinate System . . . . . . . . 5-17

5-14. Single IUS/Spacecraft Installation .......... . 5-1ל

5-15. Spacecraft-IUS Electrical Interfaces . . . . . . . . 5-2U

5-16. Telemetry and Command Functional Interfaces with lUs and Shuttle (Attached Phase). . . . . . . . . . . 5-21

5-17. Telemetry and Command Functional Interfaces with IUS ( Vetached Phase) . . . . . . . . . . . . 5-23 
SECIIUN 1

INTKODUCTION

SP-100 is the designation for a nuclear reactor-based power plant being developed for both civil and military missions beginning in the lyyus for such potential space applications as communication satellites, space radar, electric propulsion and space stations. Typically, a system using the SP-lUU along with a selected upper stage system would be launched by the National Space Transportation System (NSTS) Space Shuttle System into a nearearth orbit, deployed, and through upper stage propulsion burn(s) be inserted/ transferred to its mission orbit. The nature of the advanced design br-luU gives rise to a set of issues that require special attention to assure that payloads using this power plant are physically and functionally compatible with the NSIS and meet the safety requirements thereof. The purpose of this document is to define and present the requirements and interface provisions that, when satisfied, will ensure technical compability between SP-lOU systems and the NSTS.

Following an overview description of the NSTS is a presentation of the typical Shuttle/upper stage ground and flight operations. The Shuttle performance capabilities are then summarized, followed by summary performance capabilities of four NSTS upper stages that could be selected for achieving orbit transfer from the Shuttle parking orbit. The process by which an SP-luU would be integrated with the upper stage and with the space shuttle vehicle is then explained. Payload accommodations and interface requirements/constraints provided by the Shuttle system are high-lighted (primarily by reference), followed by the interface requirements and constraints provided by the four potential upper stages. Finally, requirements for interface verification are then presented.

It should be pointed out that although the SP-100 design utilizes a nuclear reactor power source, the reactor would be inert with insignificant radiation levels during all prelaunch and launch operations. The reactor will be designed to remain subcritical in all accident modes, and would not be started until after the SP-1OU payload is deployed from the shuttle and inserted into a nuclear-safe orbit. Because of the security aspects associated with the presence of nuclear materials, special security precautions would be required during the prelaunch operations. Based on a preliminary review of both the nuclear reactor safety and security issues, however, there do not seem to be any problems peculiar to the SP-1OU design that would prevent the launch of SP-lUC by NSTS. Potentially, SP-1UC could also contain a radioisotope thermoelectric generator ( $\mathrm{KTG}$ ) auxiliary power source with a design similar to the Galileo KIG. Should an RTG be utilized, it is expected that the various procedures and precautions established for the Galileo application would be acceptable and applicable for SP-lOG. 
SECTION 2

NSTS OVERVIEW DESCRIPTION

\section{$2.1 \quad$ NSTS DEFINITION AND TERMINOLOGY}

The NSTS consists of the Space Shuttle System (SSS); various upper stages; the ground support system at the Eastern and Western Launch Sites (ELS and WLS); and the mission operations system, including the Tracking and Data Relay Satellite System (TDRSS). The SSS provides the Space Shuttle Vehicle (SSV) flight system, the NSTS launch and landing sites at ELS and wLS where the SSV is processed and launched, and the NSTS Mission and Control Center at Johnson Space Center. (JSC) which plans and supports all NSTS missions. Comprising the flight system is the Orbiter, an external tank and two solid rocket boosters (SRBs).

The key source documents to be used by potential users of the Space Shuttle System are JSC 07700 , Volume XIV (Ref. 1) and its Attachment 1 (Ref. 2). These documents are the official, controlled set of Space Shuttle capabilities and interfacing provisions by which payload planning and design are to be conducted. Reference 2 depicts specific definitions of payload interfaces, and for convenience is identified separately from Vol. XIV (Ref. 1), which presents general payload accommodation data.

The terminology used in this report generally conforms to that de$f$ ined in Refs. 1 and 2. For this report it is assumed that the $S P-100$ is the only user of the Shuttle for the assigned launch. "Payload" then is everything in the cargo bay, and as such would comprise the detachable payload, airborne support equipment (ASE), and any mission-peculiar equipment. The detachable payload is the integrated SP-100 Flight System (SFS) and upper stage that are deployed from the Orbiter. The SP-100 flight system would comprise the SP-100 power module and the spacecraft (including the spacecraft/ upper stage adapter). In some sections of the report the SP-100 Flight system is variously referred to as "SP-100" and "Spacecraft", but this should not be confusing in the context in which such terms are used.

\subsection{GROUND AND FLIGHT OPERATIONS SCENARIO}

The sequence of operations associated with an NSTS-launched SP-100 payload from Kennedy Space Center (KSC) can be classified into the following phases: (a) pre-launch, (b) ascent-to-orbit, (c) on-orbit operations (cargo bay doors closed), (d) on-orbit operations (cargo bay doors open, and including deployment of the payload from the Orbiter), (e) post-deployment and, if required, (f) abort (including reentry and landing). Typical functions and activities that could occur during these operations and that the payload would have to consider during early design are summarized below. For purposes of describing the pre-launch operations, it is assumed that the payload is vertically integrated into the Orbiter and that the payload is for a NASA mission.

Services provided by the Orbiter at the launch pad are described in paragraph 5 of Ref. 1. Ref. 3 provides official information on the launch site capabilities and processing guidelines for the launch site operations. 
2.2.1 Pre-Launch (Launch Site Operations)

It is expected that the SP-100 Flight System will be delivered to KSC in three main units: spacecraft, power module, and RTG(s)s (if used). The spacecraft and power module will be transported to the Payload Processing Facility ( $P P F$ ) and Hazardous Processing Facility (HPF), respectively, for receiving inspection and assembly/servicing/checkout as required. Security and health physics services for the power module throughout all ground operations will be provided by KSC. The spacecraft will be delivered to the HPF for servicing as required and assembled to the power module. The RTGs will be delivered to the KSC RTG storage facility to undergo power verification, test, servicing and mechanical preparations, prior to being transferred to the HPF for RTG compatibility tests and to the Rotating Service Structure (RSS) at the pad for installation into the flight system. When al1 HPF operations have been completed, the integrated module/ spacecraft will be transported to the Vertical Processing Facility (VPF) for mating with the upper stage and cargo interface verification testing using the cargo integration test equipment (CITE). An end-to-end test will be conducted, if required, after the CITE tests. Finally, an ordnance systems test would be conducted and cargo closeout activities initiated. Upon completion of the VPF operations, the payload would be installed into the multimission support equipment canister and transferred to the pad for installation into the RSS. Once at the launch pad the canister would be hoisted into position and the payload extracted from the canister by the payload ground-handling mechanism (PGHM) and retracted into the RSS. At the appropriate time the payload would be inserted into the orbiter cargo bay using the PGHM. The RTGs (if used) would be installed and Shuttle/payload interface verification tests conducted, followed by end-to-end data and command tests (if required). Any SP-100 Flight System "carry-on umbilical cable" would then be removed, the Shuttle cargo bay doors closed, and final countdown to launch commenced.

\subsubsection{Ascent}

During ascent, the cargo element should be as quiescent as possible, consistent with cargo element operations to avoid hazardous situations that could result in an aborted flight or present a hazard to the crew or Shuttle.

\subsubsection{On-Orbit Operations (cargo bay doors open and closed)}

The Orbiter cargo bay doors should be assumed to be opened no sooner than 1 hour after launch and no later than 3 hours after launch (if not opened 3 hours after launch, the Orbiter will return and landing will be completed by launch +6.5 hours maximum). In general, the Orbiter will maintain a payload bay-to-earth orientation except for periods when the payload needs reorientation for establishing reference attitudes to be used subsequent to deployment. Expected Orbiter pointing accuracies are described in para. 3.2 of Ref. 1 .

Deployment of the payload will be controlled by the flight crew, with ground assistance as required. Typically, the orbiter primary reaction control system (PRCS) will be deactivated, the payload rotated to the deployment attitude, and deployment will occur by a separation signal from the 
Orbiter to the payload. Yeans of deployment will be the responsidility of the payload. In the event of an aborted deployment, the payload must have the capability to be reconfigured to a safe condition for landing.

\subsubsection{Detached Phase}

After deployment, the payload must coast for the period needed to achieve a safe distance from the Orbiter before the propulsive stage firing and/or deployment/separation of a payload appendage or separable device. The safety requirements associated with such operations are detailed in Ref. 4.

\subsection{SSV PERFORMANCE CAPABILITY}

Figure 2-1 shows total cargo weight as a function of circular orbit altitude for delivery flights from KSC at an inclination of 28.5 degrees. It should be noted that these capabilities are nominal, near-term values, and that specific performance expectations for particular Shuttle vehicles and other program varıables will be made available by JSC when needed and requested.

For estimates of on-orbit capabilities of such parameters as stay time, navigation accuracy, pointing accuracy, attitude hold duration, etc., see paragraph 3.2, Ref. 1 .

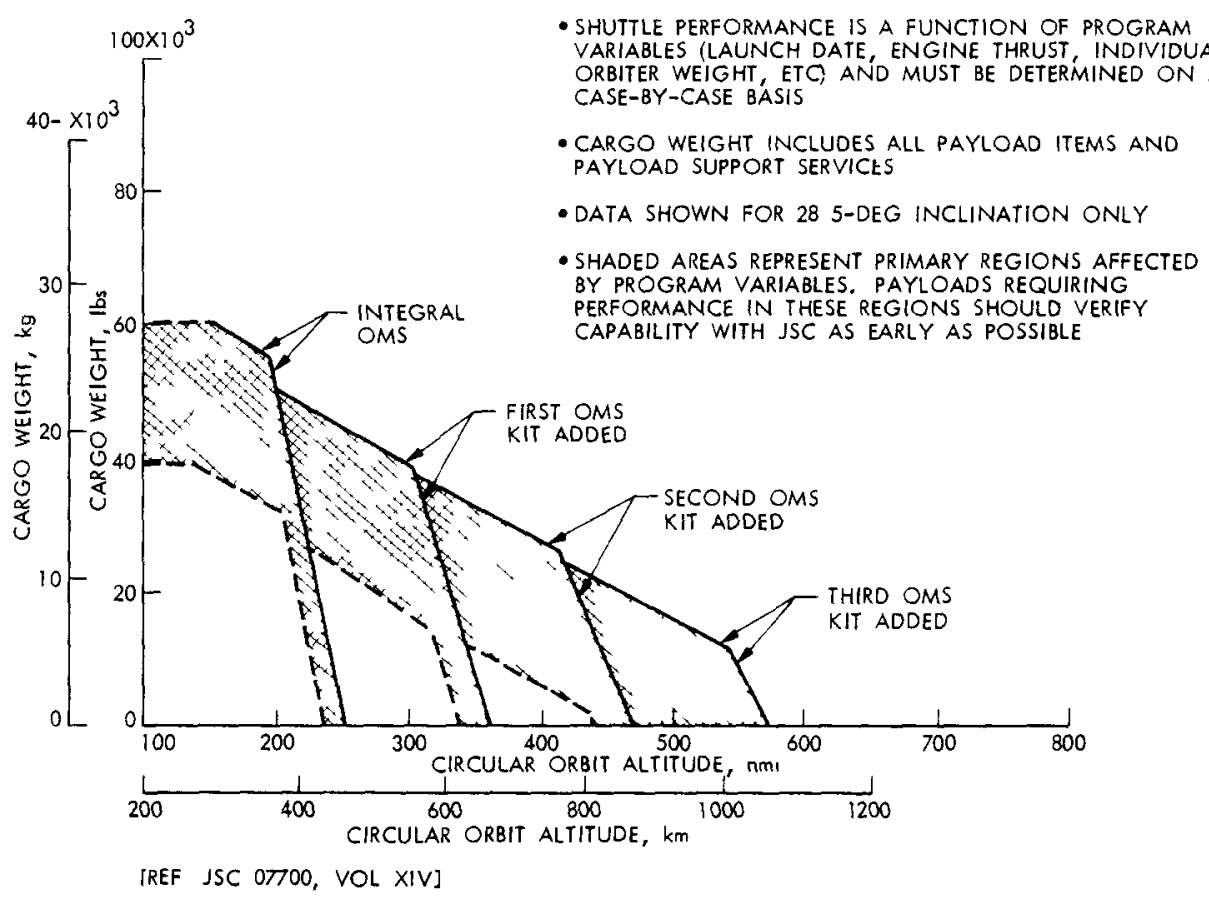

Figure 2-1. Near-Term Cargo weight Versus Circular Orbital Altitude - KSC Launch, Delivery Only 


\subsection{SSV/UPPER STAGE PERFORIAANCE ESTIMATES}

Estimated performance capabilities of various upper stages for orbit transfer from a 150-nmi Shuttle parking orbit are presented in Figures $2-2$ through $2-11$.

Figure 2-2 shows the delta-V available from the Centaur $G$ as a function of payload mass for orbit inclinations between 28.5 and 90 degrees. Orbital inclinations between 57 and 70 degrees are not available from Cape Kennedy due to restrictions on Shuttle launch azimuth. The dashed line portions of the curves indicate that Centaur propellant must be offloaded to stay within the cargo capability of the Shuttle. Figure 2-3 shows the performance capability in terms of circular orbit altitude achievable as a function of payload mass. Figures $2-4$ and $2-5$ show similar information for the Centaur $G^{\prime}$.

Figure 2-6 presents the delta-V capability of the Transfer Orbit Stage (TOS) currently under development. Delta-Vs in excess of $3200 \mathrm{~m} / \mathrm{s}$ will result in planetary escape. This solid propellant stage cannot be restarted (as is the case with Centaur $G$ and $G^{\prime}$ ), so the TOS performance is shown in Figure 2-7 in terms of the apogee of the transfer orbit as a function of payload mass. The minimum delta-V from the TOS is limited by the amount of propellant offload $(50 \%)$ allowed. Figure $2-8$ presents the additional delta-V needed to circularize the transfer orbit as a function of circular orbit altitude. This circularization capability would necessarily be provided by the payload.

Figures 2-9 through 2-11 present the performance capability of the two-stage (standard) IUS for orbit transfers from a $150-\mathrm{nmi}$ (278 km) Shuttle parking orbit. Performance is shown in terms of delta-V available from eacn of the two stages. Figure 2-9 presents the delta-V capability of the IUS stages as a function of payload mass. The total delta- $V$ available for a given payload is obtained by adding the capability of both stages. Figures $2-10$ and 2-11 present the delta-V and altitude capabilities of the IUS stages when delivering a payload to circular orbit. For payloads less than $3300 \mathrm{~kg}$, a fully loaded Stage 1 is used along with an offloaded Stage 2. For payloads greater than $3300 \mathrm{~kg}$, an offloaded Stage 1 is supplemented by a fully loaded Stage 2. It should be noted that offloading of either stage is limited to $50 \%$. 


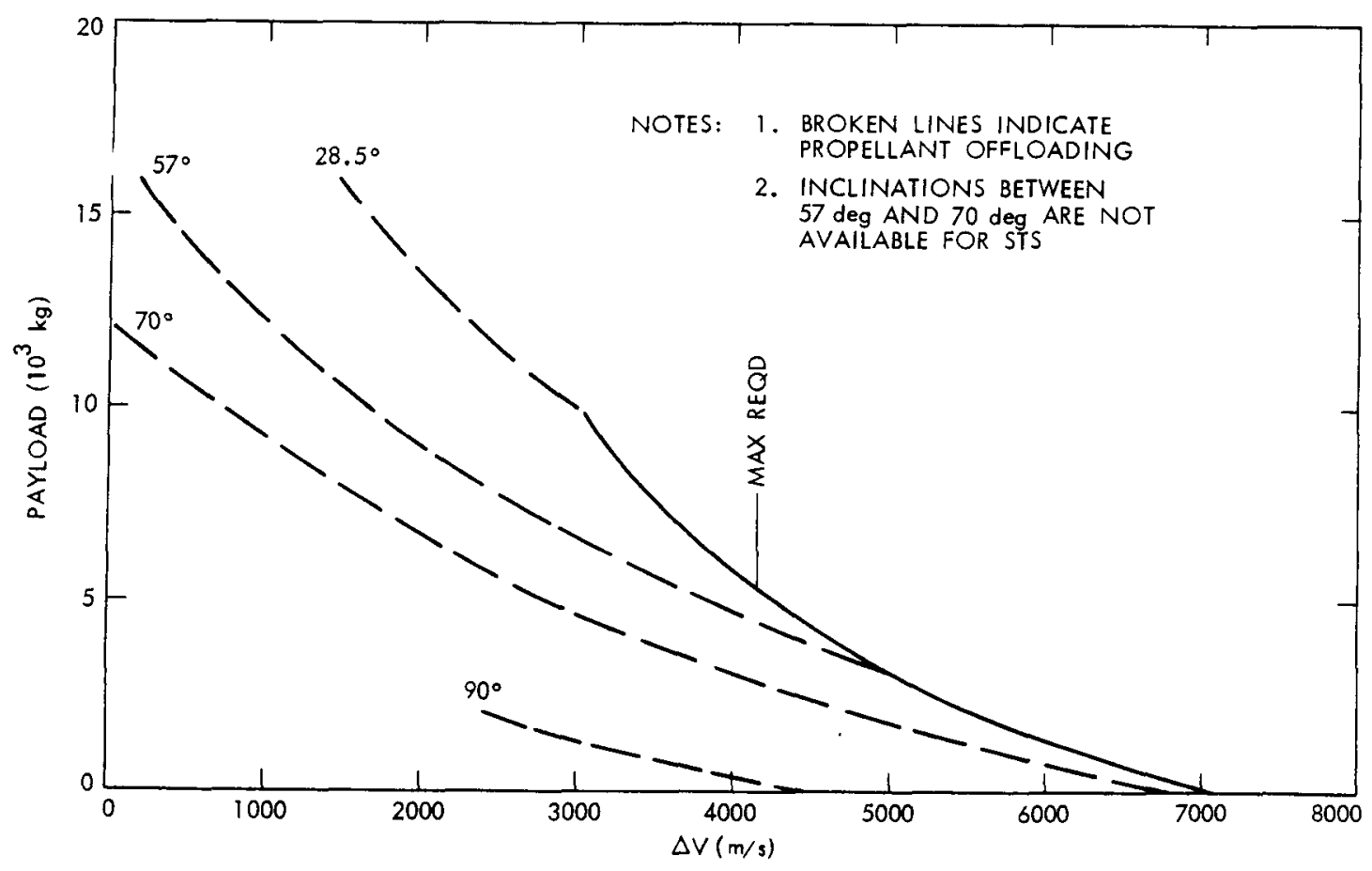

Figure 2-2. Centaur G Performance: Payload Versus Velocity

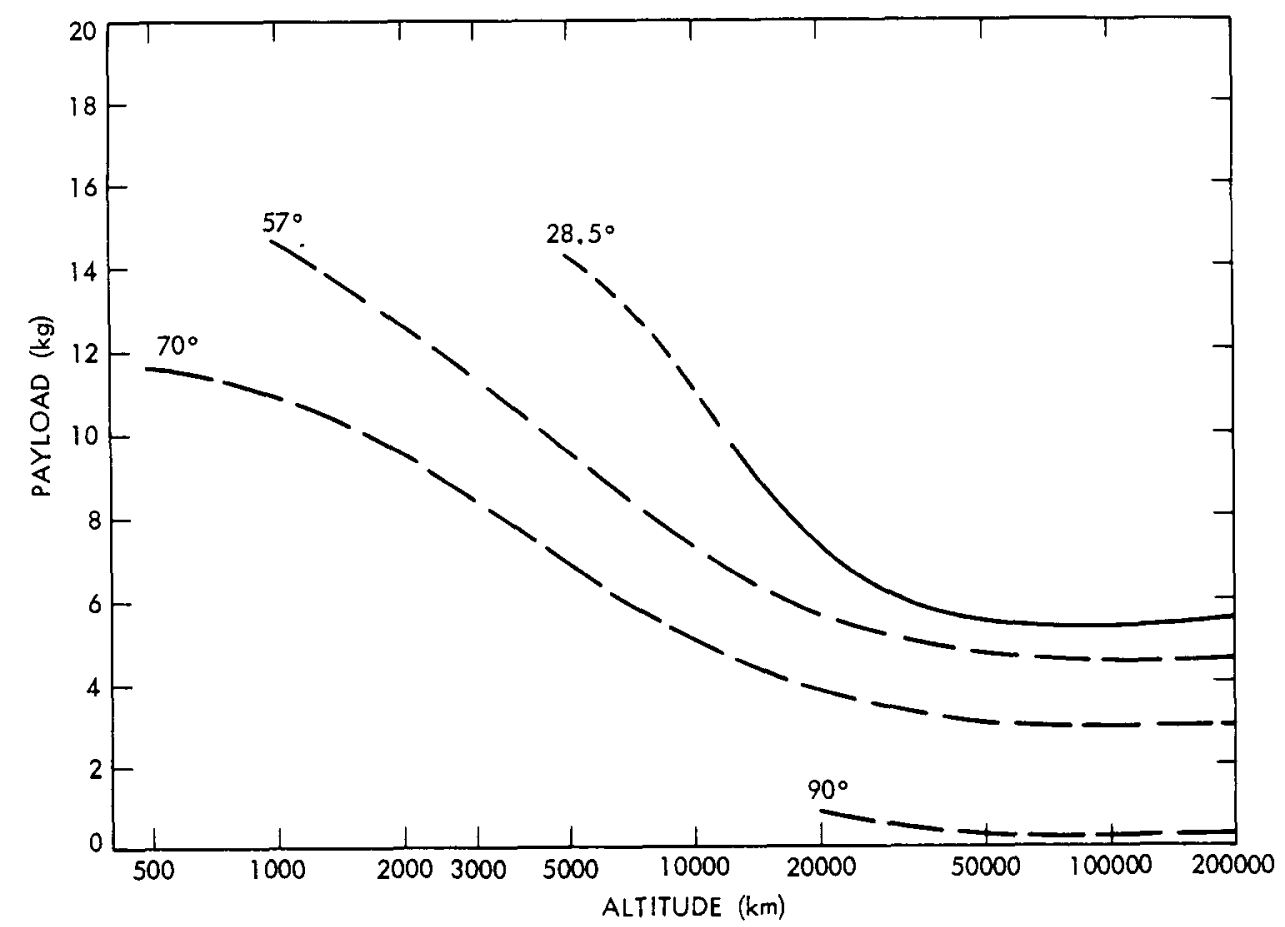

Figure 2-3. Centaur G Performance: Payload Versus Altitude, Circular Orbit 


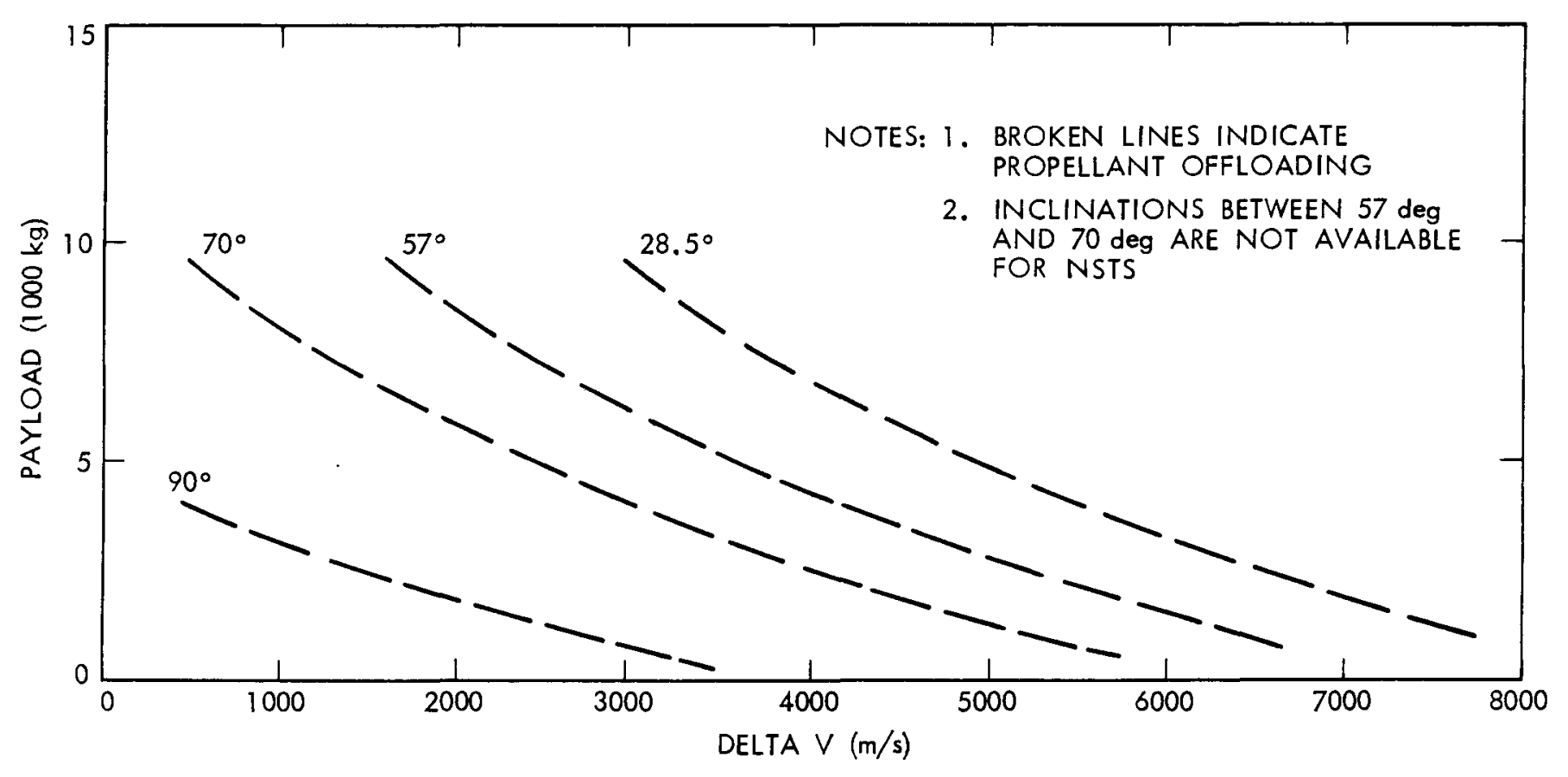

Figure 2-4. Centaur G' Performance

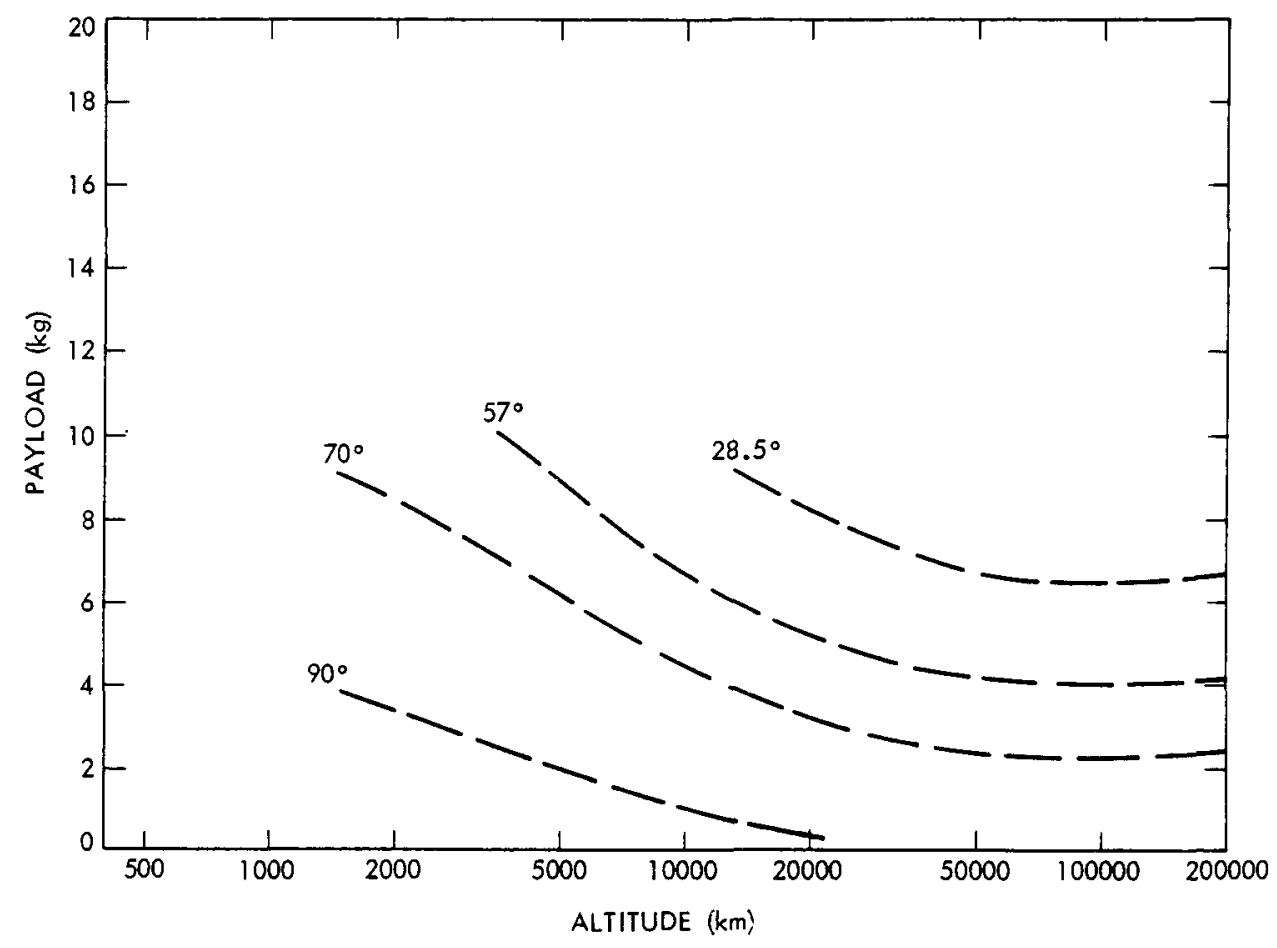

Figure 2-5. Centaur G' Performance: Payload Versus Altitude, Circular Orit 


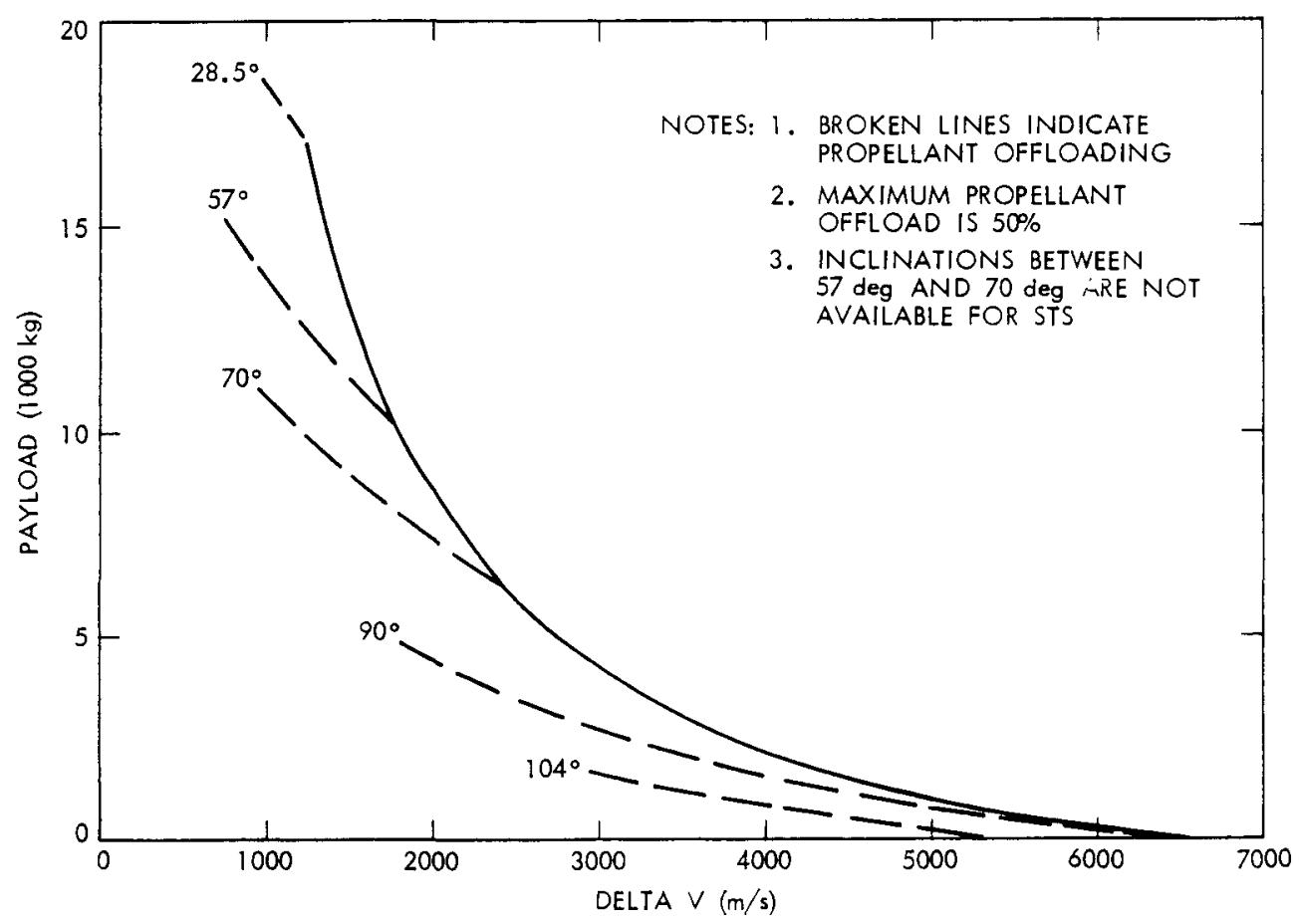

Figure 2-6. TOS Performance: Payload Versus Velocity

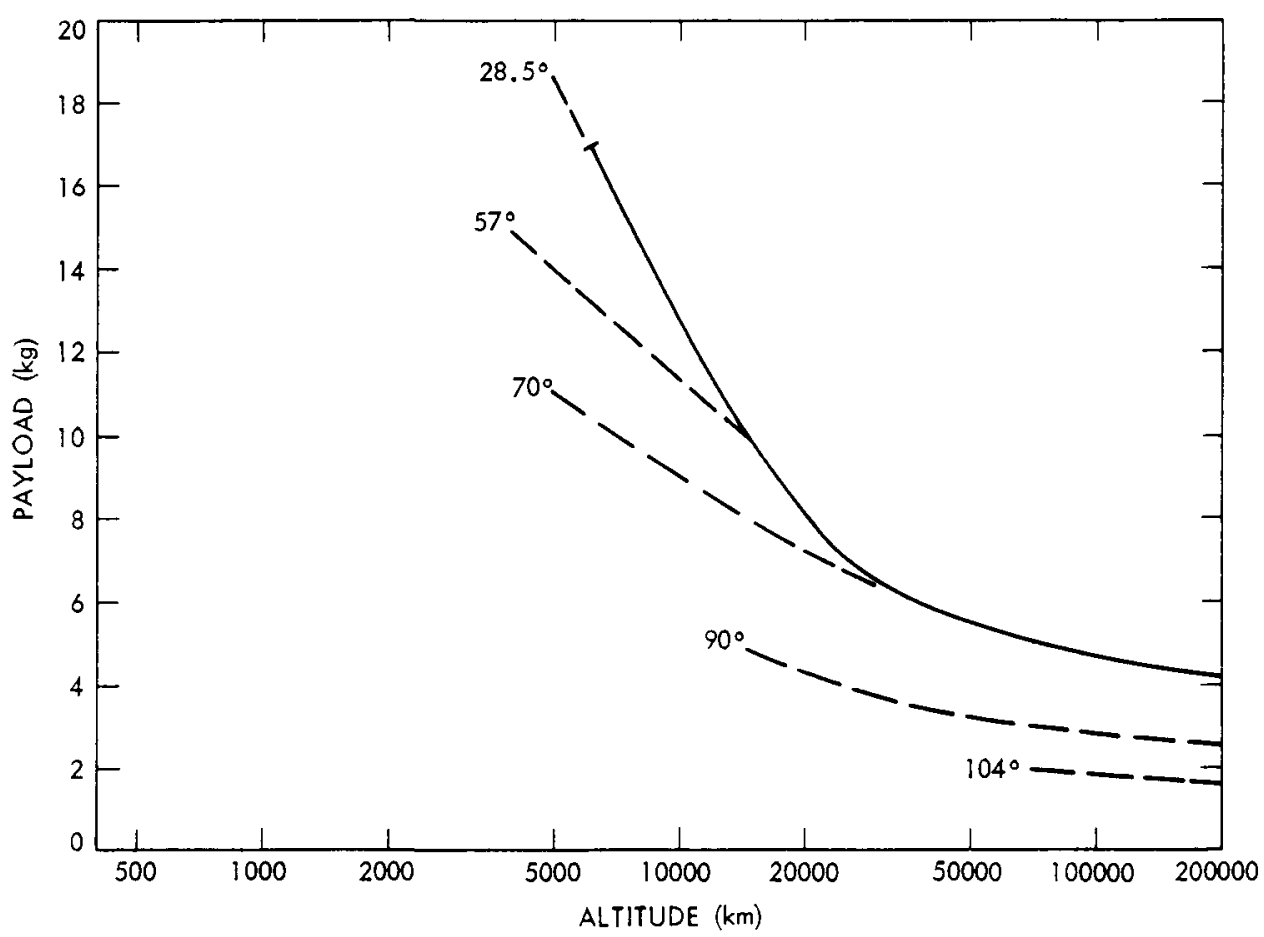

Figure 2-7. TOS Performance: Paylnad Versus Altitude, Transfer Orbit 


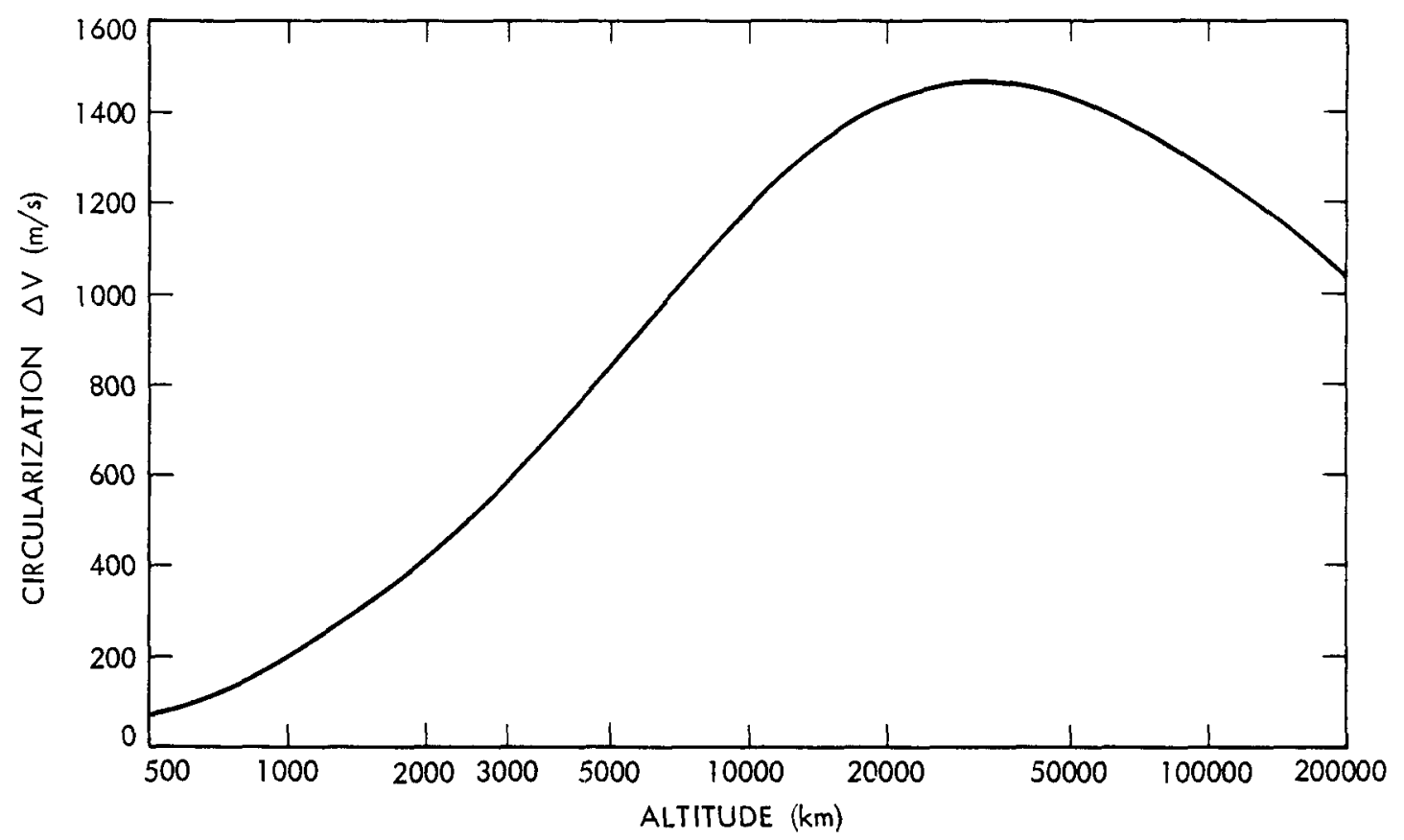

Figure 2- $\delta$. TOS Performance, Circularization $\Delta V$

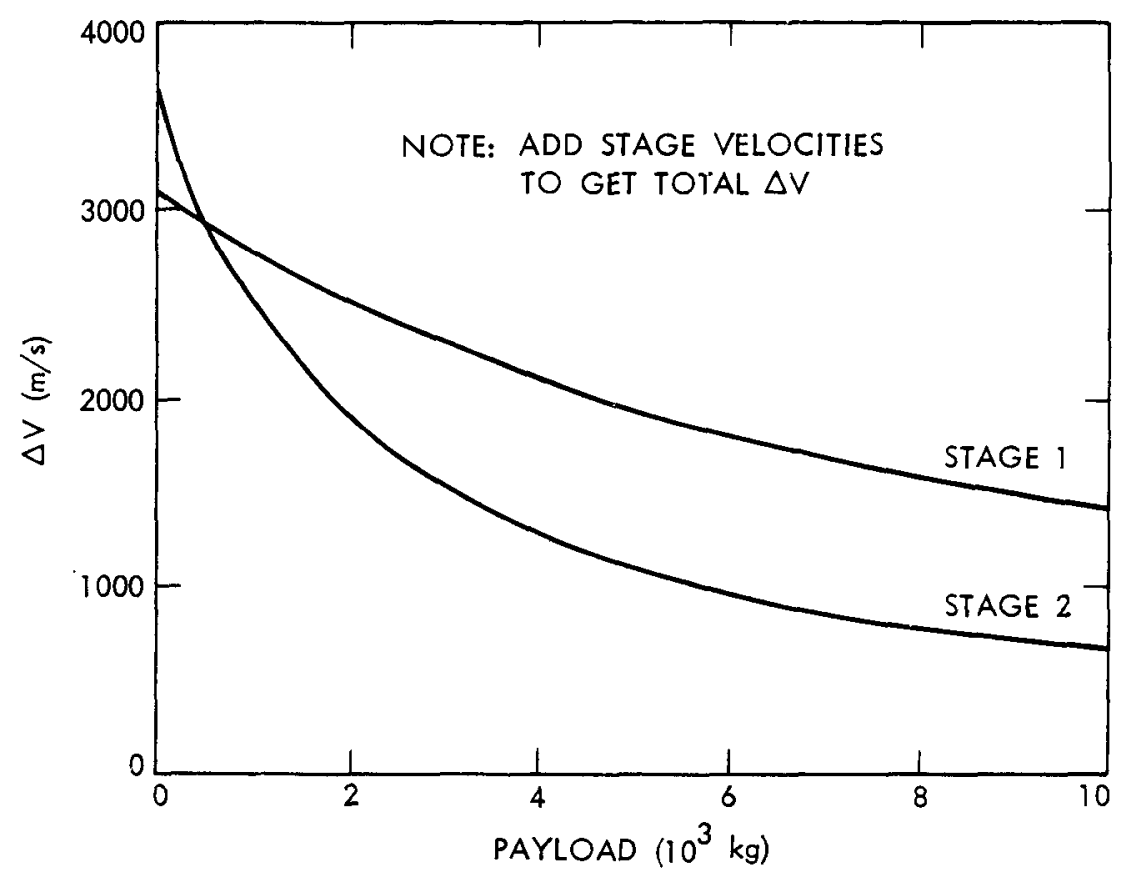

Figure ¿-y. IOS Velocity, Capability Versus Fayload, Both Sides Fully Loaded 


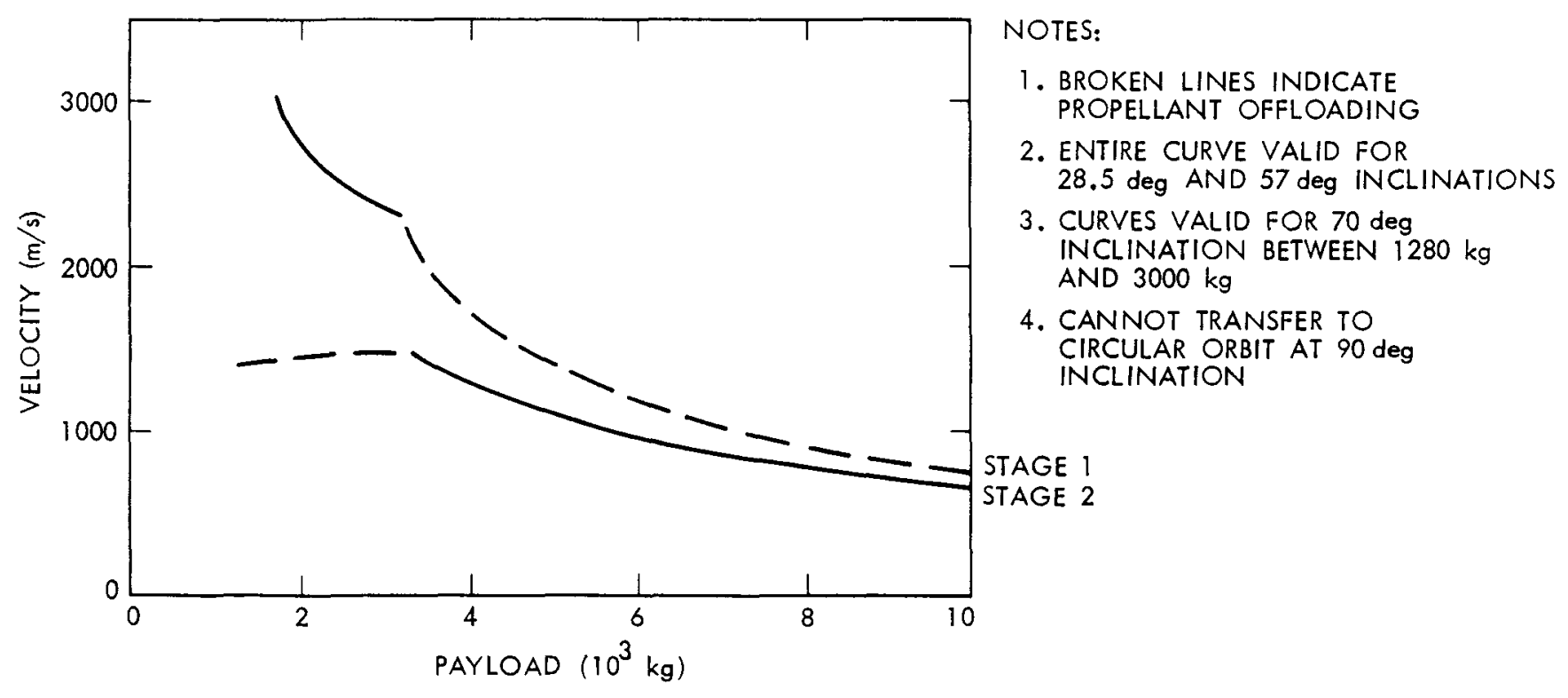

Figure 2-10. IUS Performance, Payload Versus Velocity, Circular Orbit 


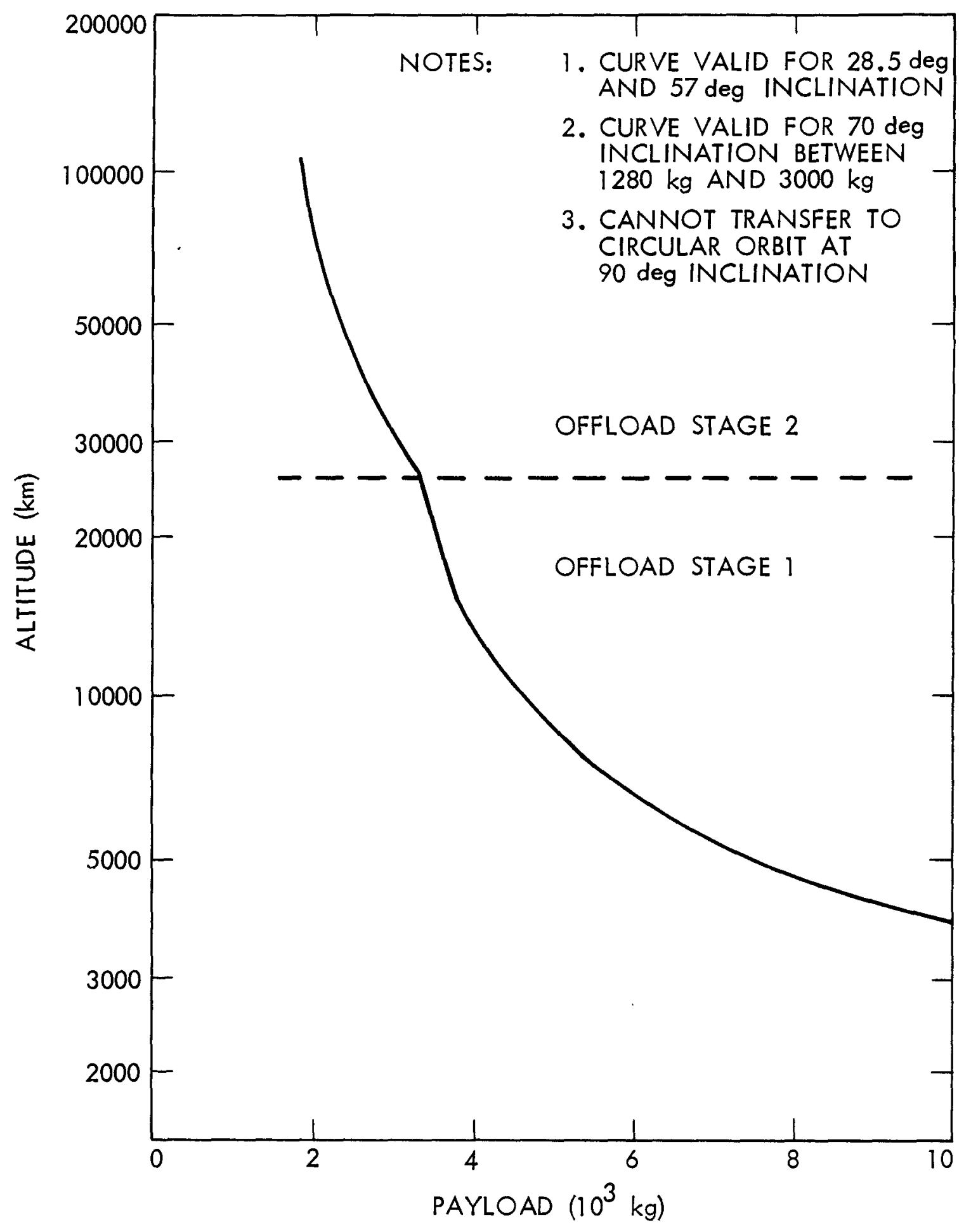

Figure 2-11. IUS Performance: Payload Versus Altitude, Circular Grtit 


\section{SECTION 3 \\ INSTS/PAYLOAD INTEGRATION PROCESS}

The process of integrating payloads with the NSTS is explained in Ref. 5. The following paragraphs summarize some of the steps necessary for, and the requirements and activities associated with, the process.

\section{$3.1 \quad$ PROJECT/NSTS INTERFACING AND PLANNING}

Formal interaction between the SP-100 project, the appropriate NASA Program Office, and the NASA NSTS utilization office, is initiated at the time of project start by a "Request for Flight Assignment" (Form 100). The Project is formally recognized at this time, and activity is initiated between the Project and the STS Mission Integration Office at JSC to resolve Shuttle/payload integration issues. A project engineer is assigned as the single point of contact from the JSC STS Payload Integration Office. He will coordinate all meetings and contacts with the NSTS element throughout the integration process, and will assure that integration activities and analyses are performed to support both the Shuttle requirements and the payload requirements. The flight assignment process, an internal activity of the NSTS, will develop and maintain a cargo manifest and flight assignment schedule.

The two controlling documents that define the interfaces and integration processes relative to the NSTS/Payload integration and interface engineering are the Payload Integration Plan (PIP) and the Payload/ivSTS Interface Control Document (ICD).

The PIP is initiated when the payload has been assigned to the JSC NSTS Operations Program Office. Programmatic and technical relationships between NSTS and the Project are defined in the jointly prepared PIP. It will be the controlling document between the NSTS and the project, and will define management roles, working relationships, and responsibilities. In addition, the PIP defines the technical baseline for implementation; establishes guidelines and constraints for integration and planning; defines integration tasks to be accomplished; establishes operational support requirements, interface verification requirements, and control schedules for all major integration activities; defines safety requirements; and summarizes the optional services. The outline of the basic PIP is shown in Ref. 5. The format and contents of the PIP for deployable payloads and those with direct Orbiter interface are provided in Ref. 6. In addition to the PIP, 10 PIP annexes developed jointly by the Project and the NSTS provide detailed data to support iNSTS flight and ground operations. There is a standard format provided for these annexes and assistance is provided by JSC in developing the documents. The payload requirements from these annexes are integrated with the NSTS standard procedures and ultimately result in flight and ground operations implementation documentation. A given mission may not require all annexes.

The Project will work with JSC to develop the Payload/NSTS ICD, which will define the payload and NSTS integration and interface requirements and constraints, and will be written on a line-by-line basis against Ref. 2 . The ICD will reflect the Project system interface requirements and constraints 
to ensure complete systems programmatic and technical compatibility. The mechanical and electrical interface control drawings will be an integral part of this ICD. The ICD is produced and approved by JSC and then submitted to the project for approval.

3.2 INIEGKATION/INTERFACE WOKKING GKOUPS

Integration/interface working groups are used by the NSIS Hayload Integration Office as a means of accomplishing the integration and flight implementation process. The working groups are supported by all organizations necessary to assure a successful integration and launch of the shuttle with the particular cargo. Typically, the working groups will be governed by an interface management working group (IMWG), co-chaired by representatives trom NSTS and the Project. Six working groups generally are formed: Structural/ Mechanica1, Thermal, Flight Operations, Avionics Software, Ground Operations, and Mission Flight Design.

Specific scheduling of the interface working group activities with milestones and deliverables will be tied to the project development and NSIS operations schedules. The IMlkG should meet as soon as possible after lission Project start to begin to establish the joint activities schedule.

\subsection{NSTS/KSC OPERATIUNS/INTERFACE PLANNING}

Kennedy Space Center is responsible for NSTS and cargo-ground facilities and operations at KSC including ground safety and all support activity. Requirements that are established for ground operations are documented in the PIP Annex $\delta$, the "Launch Site Support Plan." The Ground Operations Working Group provides the forum for identifying these requirements, defining and controlling the payload-to-KSC interfaces, and defining launch activities. In addition to these formal interfaces with $\mathrm{KSC}$, additional activity is required to support cargo test team activity; develop launch processing plans, standalone test procedures, and inputs to integrated test procedures; abort planning; and present the KSC safety reviews as discussed in paragraph 3.4 below.

\section{$3.4 \quad$ SAFETY KEVIEWS}

Al1 STS users must implement the payload system safety requirements of the NASA headquarters Handbook, "Safety Policy and Requirements for Fayloads Using the Space Iransportation Systems" (Kef. 4), and "Space Transportation System Payload Ground Safety Handbook" (Ref. 7). Guidelines and instructions for implementing these requirements are provided in kef. 8 . Briefly, the STS operator reviews and evaluates the payload safety data, evaluates safetyrelated modifications, and provides approval/concurrence or requests further action. As many as four flight and ground safety reviews will be conaucted (Phase 0 through Phase III) with an initial introductory and guideline meeting held with the mission project. Ubjectives of each review are described in Ref. 8. The phased safety reviews are intended to occur at times of increasing maturity of the flight system design. Timing of the reviews for planning purposes can be assumed as follows: Phase 0 - concept; Phase I - Preliminary 
Design Review; Phase [I - Critical Design Review; Phase [LI - hardware delivery. Actual schedules will be established with the project by JSC/KSC on the basis of the project schedule.

\subsection{NSTS/KSC MAJOR REVIEWS}

Other major reviews are conducted by the NASA Headquarters, the JSC Mission Integration Office, and KSC to assess the implementation of the cargo integration activity. These reviews, listed below, aid both the STS and the user in assuring that the launch vehicle and cargo are ready for the mission.

Cargo Integration Review (CIR): The first review of consequence held by JSC where all cargo elements for a specific flight are reviewed together to assure they can be physically and functionally integrated into the flight.

Flight Operations Review (FOR): Review to status the STS flight operations implementation development.

Integrated Hardware and Software Review (IH/SR): Review to ensure the STS-provided hardware and software are compatible.

Ground Operations Review (GOR): Review to assure readiness and agreement to the overall support of the launch and landing site for ground integration activities.

Flight Readiness Review (FRR): Review conducted to verify that all cargo/STS integration activities are complete.

3.6 SP-100 FLIGHT SYSTEM TO UPPER STAGE INTEGRATION

The following discussion explains the process by which the Flight System is integrated with the upper stage (US). This approach assumes a NASA mission, with the US represented by a NASA Center payload and is based primarily on Galileo experience.

To implement the integration of the Flight System with the upper stage, two jointly chaired panels, the Mission Integration Panel (MIP) and the Mission Design Panel (MDP), would be established. The panels would consist of representatives of the SP-100 Project, Shuttle/Upper Stage Project, NASA Headquarters, and NSTS (JSC, KSC and supporting contractors). The purpose of the MIP would be to provide the SP-100 Project and the Shuttle/US Project assurance that the SFS/US integration requirements are accomplished on mutually acceptable schedules and with completely satisfactory technical resolution. The purpose of the MDP would be to interchange mission, SFS and upper stage system technical information for the development and analyses of launch vehicle performance, launch period, trajectories, and guidance and control for the SP-100 mission. 
SECTION 4

SPACE SHUTTLE-TO-PAYLOAD INTERFACE CHARACTERISTICS

The following sections summarize the Space Shuttle capabilities and payload interfaces provided by the baseline Shuttle System for cargo use as presented in Refs. 1 and 2. The constraints that shall be observed by payloads using the interfaces defined are included also. The information presented here is in summary form; Refs. 1 and 2 should be consulted if additional data is needed for a particular interface. It should be emphasized that the accommodations and interfaces described below are those that are provided to the total shuttle cargo. Section 5 summarizes the pertinent characteristics and constraints at the SP-100 Flight system-to-upper stage interface for four candidate upper stages: Centaur G, Centaur $G^{\prime}$, Transfer Orbit Stage (TOS), and the Inertial Upper Stage (IUS).

\subsection{PHYSICAL INTERFACE}

\subsubsection{Coordinate Reference Axes}

The payload coordinate system, relative to the Shuttle Orbiter coordinate systems shall be as shown in Figure 4-1. The payload $X$-axis is coincident with the Orbiter cargo bay centerline and is positive down with the Orbiter in launch position. Payload elements may choose to use a different set of coordinates, but all payload coordinate data transmitted to the Shuttle Program must be in accordance with the coordinate system illustrated in Figure 4-1.

\subsubsection{Allowable Thermal and Dynamic Envelope}

The maximum allowable payload envelope in the cargo bay shall be a clear cylindrical thermal and dynamic envelope, $15 \mathrm{feet}$ in diameter (Yo -90 to Yo +90; Zo 310 to Zo 490) and 60 feet in length (Xo 582 to Xo 1302). This envelope includes all payload thermal, dynamic and static deflections beginning with installation of the payload and ending with payload deployment or removal. Other details of the physical interface locations of the cargo bay are shown in paragraph 3.1.2, Ref. 2 .

\subsubsection{Interface Locations and Attachments}

The various Shuttle Orbiter Payload physical interfaces and locations for structural, electrical and fluid accommodations are described in paragraph 3.2.1, Ref. 2 .

Multiple attachment points are provided along the cargo bay for structural attachment of payloads to the orbiter. The attached points on bridges supported from primary frames are available at 3.933-inch increments. The payload (or payload carrier such as an upper stage or cradle) shall be supported at these locations on payload trunnions extending beyond the payload envelope in the + Yo direction at $\mathrm{ZO}_{0}=414$ and in the minus Zo direction at $\mathrm{Y}_{\mathrm{O}}=0$. 

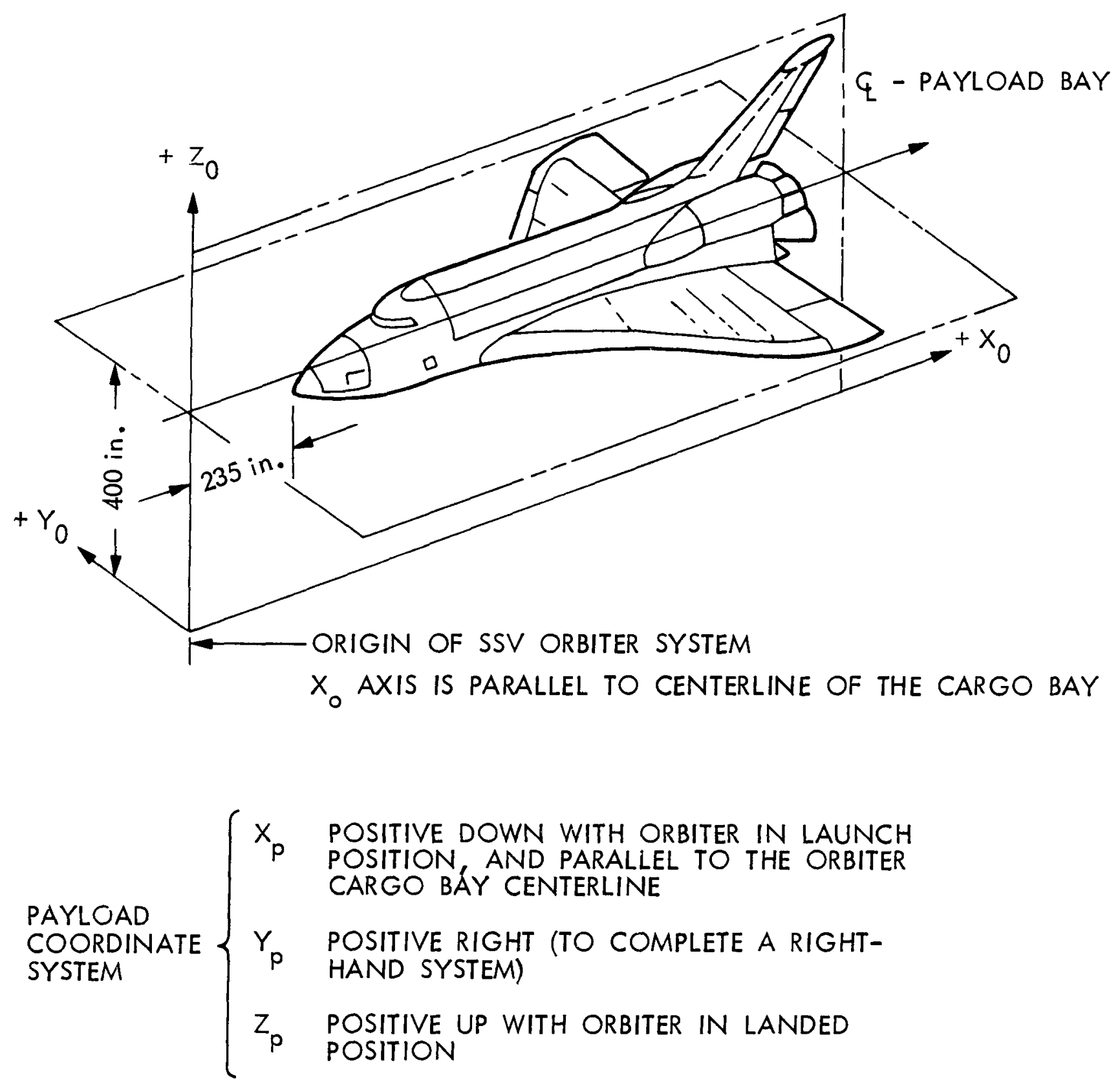

ORIGIN OF PAYLOAD COORDINATE SYSTEM APPROXIMATELY $200 \mathrm{IN} .(5.1 \mathrm{~m})$ BELOW CENTERLINE OF THE FORWARD END OF THE PAYLOAD

[REF: JSC 07700, VOL XIV, ATT. I]

Figure 4-1. SSV Orbiter Payload Coordinate System (Mechanical) 
Electrical interface accommodations are available only at the cargo element end of Standard Mixed Cargo Harness ( $\mathrm{SiCH}$ ) cables in the cargo bay. Standard interface panels are located on the port and starboard sides of the cargo bay. The electrical wiring interfaces of the SMCH accommodations, including connector and pin assignments, are given in Section 13.0, Ref. 2 .

\subsection{STRUCTURAL INTERFACES}

Paragraph 4.0, Ref. 2 details the constraints on the payload structural interface design, and the factors to be used in preliminary design of payload primary structure and for determining preliminary orbiter/cargo interface loads. The allowable cargo center of gravity (cg) limit, definition of acoustics and vibration levels in the cargo bay, and acceleration levels for various Shuttle operations and conditions are included.

Note that the latest revision of Vol. XIV, Attachment 1 (Ref 2) does not include Interface Revision Notice 235, which revises the payload preliminary design angular accelerations load factors tabulated in Tables 4.1.3-2 and 4.1.3-4, Ref. 2 .

\subsection{FLUID INTERFACES}

The Shuttle provides fluid interface provisions necessary to fill, purge, vent, and/or drain payload consummables. Physical characteristics of these interfaces for GSE cooling, payload heat exchanger, 02/N2 supply, payload purge spigots and umbilical panels are contained in para. 3.3, Ref. 2 .

\subsection{ENVIRONMENTAL CONTROL INTERFACES}

Prior to closure of the Orbiter cargo bay doors, the cargo bay atmosphere is controlled by ground support equipment (GSE), at a nominal temperature of $70^{\circ} \mathrm{F}+50 \mathrm{~F}$. Following cargo bay closure, a flow of conditioned gas (air or GN2) will be provided in the cargo bay. Unless otherwise negotiated, the inlet temperature of this gas will be $65^{\circ} \mathrm{F}+50 \mathrm{~F}$. Spigot coolant in the cargo bay is available to dedicated users; non-standard ducting is required. Cooling water from GSE is specified in Ref. 2, Section 6.4.

The Orbiter thermal capability as a function of vehicle attitude is specified in Section 6.0, Ref. 2. Typical temperature ranges at the cargo bay walls are defined in Ref. 2, para. 6.1.4. Actual temperatures are dependent upon flight parameters and cargo element configuration. The maximum temperature for the radiation panels when the doors are closed will not exceed $210^{\circ} \mathrm{F}$. For payload-active thermal control requirements, a payload heat exchanger within the Orbiter is used for transfer of heat from the payload coolant to the Orbiter's active thermal control subsystem (ATCS). Either water, Freon-2l or Freon-114 may be used by the payload as a coolant. Details of the heat exchanger service and the heat rejection capabilities provided by the Orbiter are defined in Ref. 2, para. 6.2.2. 
4.5 ELECTRICAL POWER INTERFACE

Total electrical power available to the payload is $50 \mathrm{kWh}$ at a nominal $28 \mathrm{Vdc}$ on flights up to seven days. Because of heat removal constraints imposed by the Orbiter, maximum power drawn by the cargo during the various phases of operations is limited. These limiting values, along with the DC and AC power characteristics at the interfaces, are detailed in Section 7.0, Ref. 2. Additional power is available through the installation of one electrical power system kit, which will provide $840 \mathrm{kWh}$.

\subsection{AVIONICS INTERFACES}

Avionics accommodations provided to payloads include data necessary to initialize the payload, onboard digital computation, reception of uplink commands and data, transmission of digital and wide-band data, data transmission to the detached payload, and capability to track. Services and interface characteristics of these accommodations are discussed in Section 3.0 , Ref. 2 .

\subsection{ENVIRONMENTAL REQUIREMENTS}

The natural environments to which the payload may be exposed during operation with the Space Shuttle System are described in Section 4.0, Ref. 1 . Section 10.0, Ref. 2, defines the Shuttle-induced environments, including vibration, acoustics, shock, load factors, temperature, particulates and gas environment, electromagnetic compatibility, nuclear radiation and illumination.

\subsection{OTHER INTERFACES}

Nominal locations and orientations of the various Shuttle engines and plume descriptions are presented in Section 11.0, Ref. 1. 


\title{
SECTION 5
}

\author{
INTERFACE CHARACTERISTICS AND REQUIREMENTS OF NSTS UPPER STAGES
}

This section describes the pertinent interfaces provided by four NSTS upper stages - Centaur G, Centaur $G^{\prime}$ (formerly Centaur F), Transfer Orbit Stage (TOS), and Inertial Upper Stage (IUS) - which are likely candidates for providing the additional mission energy requirements over that available from the Shuttle Orbiter for an SP-100 mission. Performance capabilities of these stages are presented in para. 2.4.

\section{$5.1 \quad$ CENTAUR}

Figures 5-1 and 5-2 show configurations of the Centaur $G$ and $G^{\prime}$, respectively, in the cargo bay with stations referenced to Shuttle coordinates. Because interfaces with the SP-100 flight system generally are the same for either Centaur $G$ or Centaur $G^{\prime}$, the interfaces described below are in terms of a "Centaur". However, each vehicle is treated separately where the interfaces are different. Refs. 9 and 10 provide technical descriptions of the Centaur G and $G^{\prime}$, respectively.

\subsubsection{Structural/Mechanical Interfaces}

5.1.1.1 Interface Locations and Attachment. The SP-100 will mechanically interface with the Centaur at the forward field joint of the Centaur equipment module at $\mathrm{Xo}_{0}=\mathrm{TBD}$. The bolt circle of this interface is 108.6 in. in diameter. Interface attachment for the Centaur $G$ will be by either an 8-point bolt arrangement or a continuous ring; the Centaur $G^{\prime}$ is via a continuous ring. Specific details of these interfaces are TBD.

The electrical interface between the $\mathrm{SP}-100$ and Centaur shall be a connector island located on the SP-100 side of the field joint on the SP-100supplied spacecraft adapter.

An insulation blanket (type TBD) will be provided by Centaur between Centaur and $\mathrm{SP}-100$ in the internal cavity between the adapter and Centaur equipment module to minimize radiant heat transfer. The blanket shall be attached to the Centaur equipment module.

5.1.1.2 SP-100 Separation from the Centaur. The SP-100/Centaur separation plane shall be on the SP-100 side of the field joint. SP-100 shall provide the mechanism that causes the separation, and also the means for initiating the sequence. The Centaur can provide the separation system ordnance power, if required.

5.1.1.3 Structure and Loads. The SP-100 F1ight System shall be designed to accommodate the flight loads of Shuttle lift-off, ascent-to-orbit, Centaurpowered flight, and Shuttle orbiter abort landings. Preliminary loads for SP-100 design may be determined from the mass acceleration curve shown in Figure 5-3 for component masses less than $1000 \mathrm{~kg}$, and from section 4.1 .3 of 


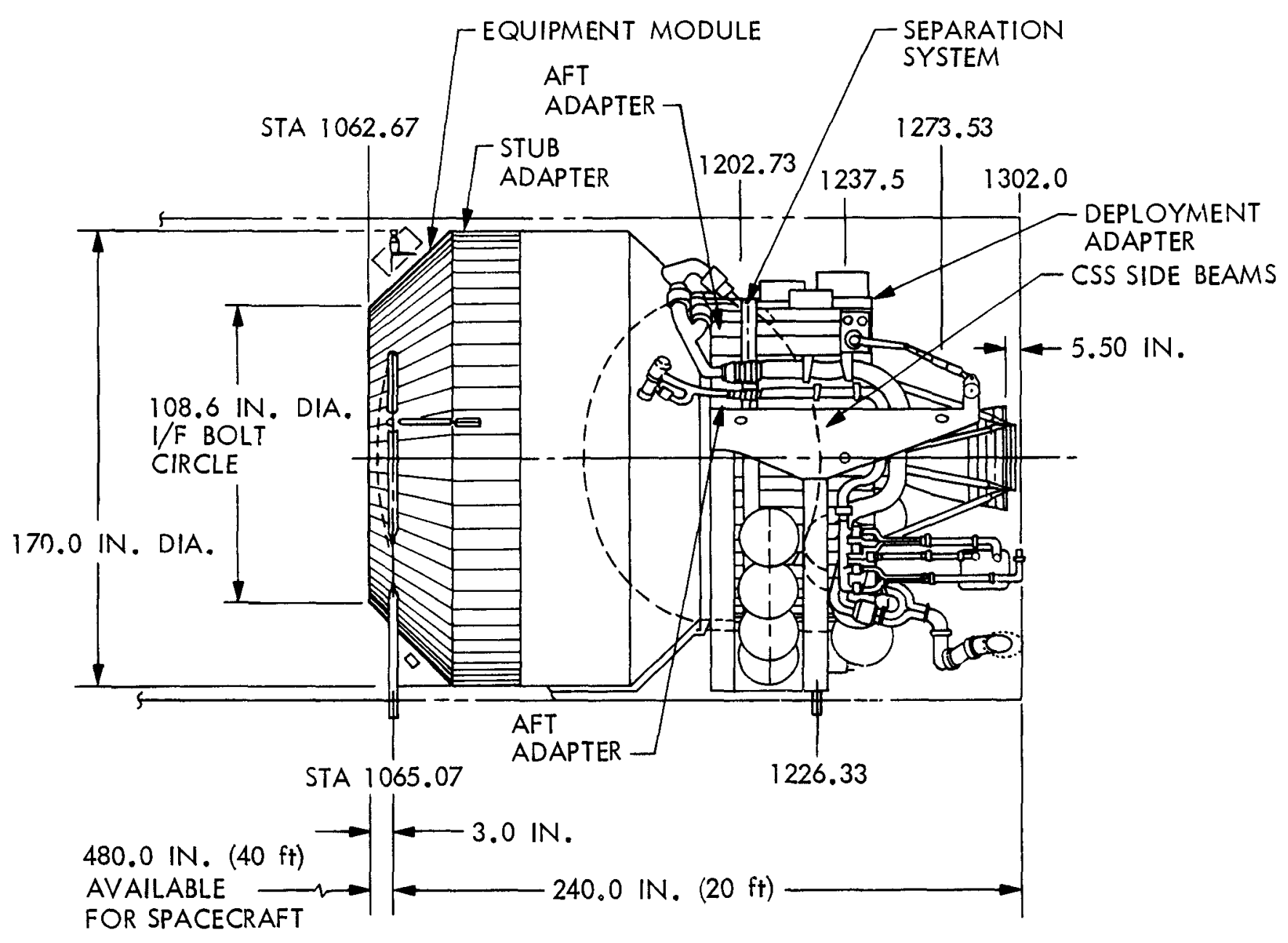

[REF: GDC CGTD-3]

Figure 5-1. Centaur G Configuration 


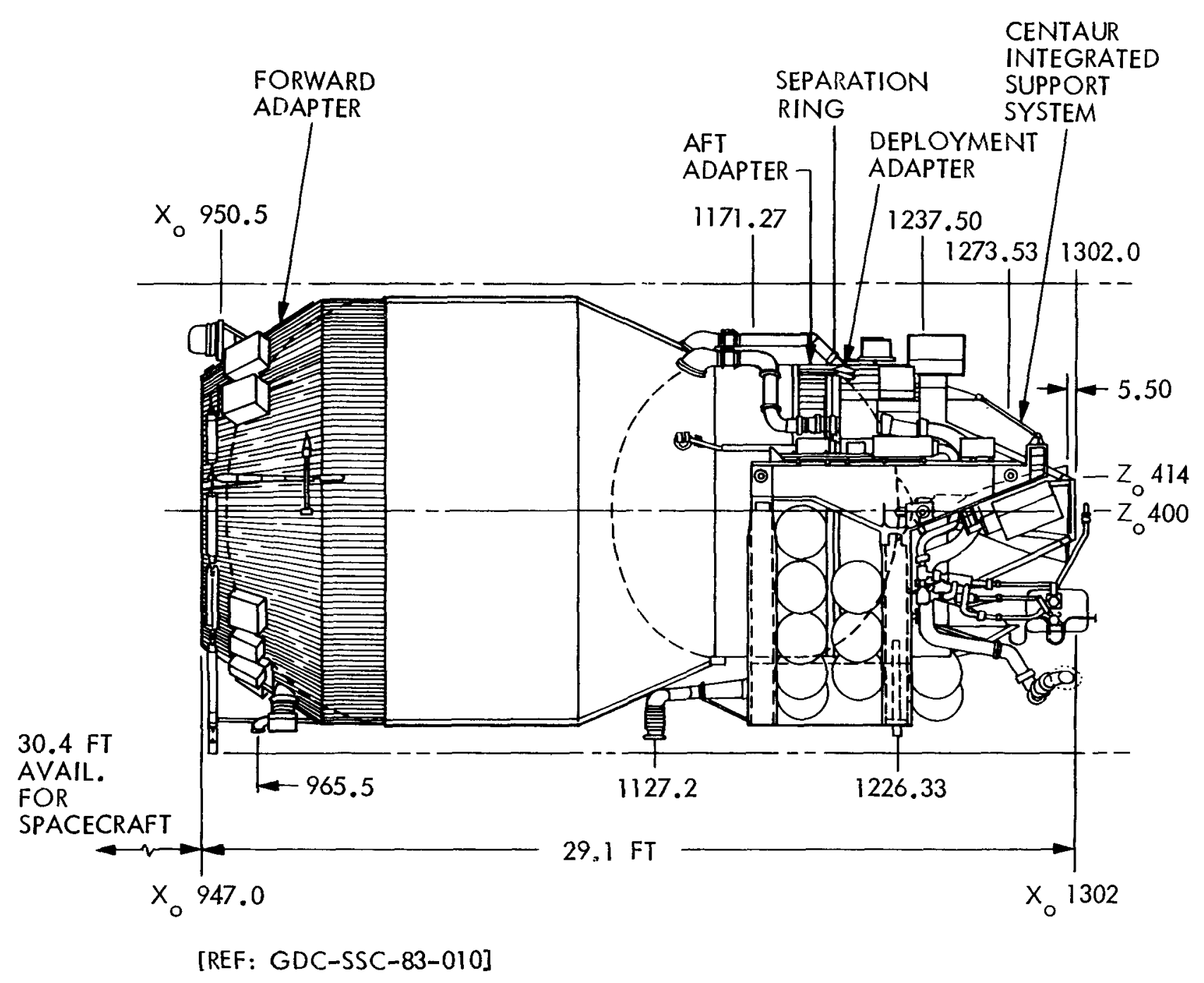




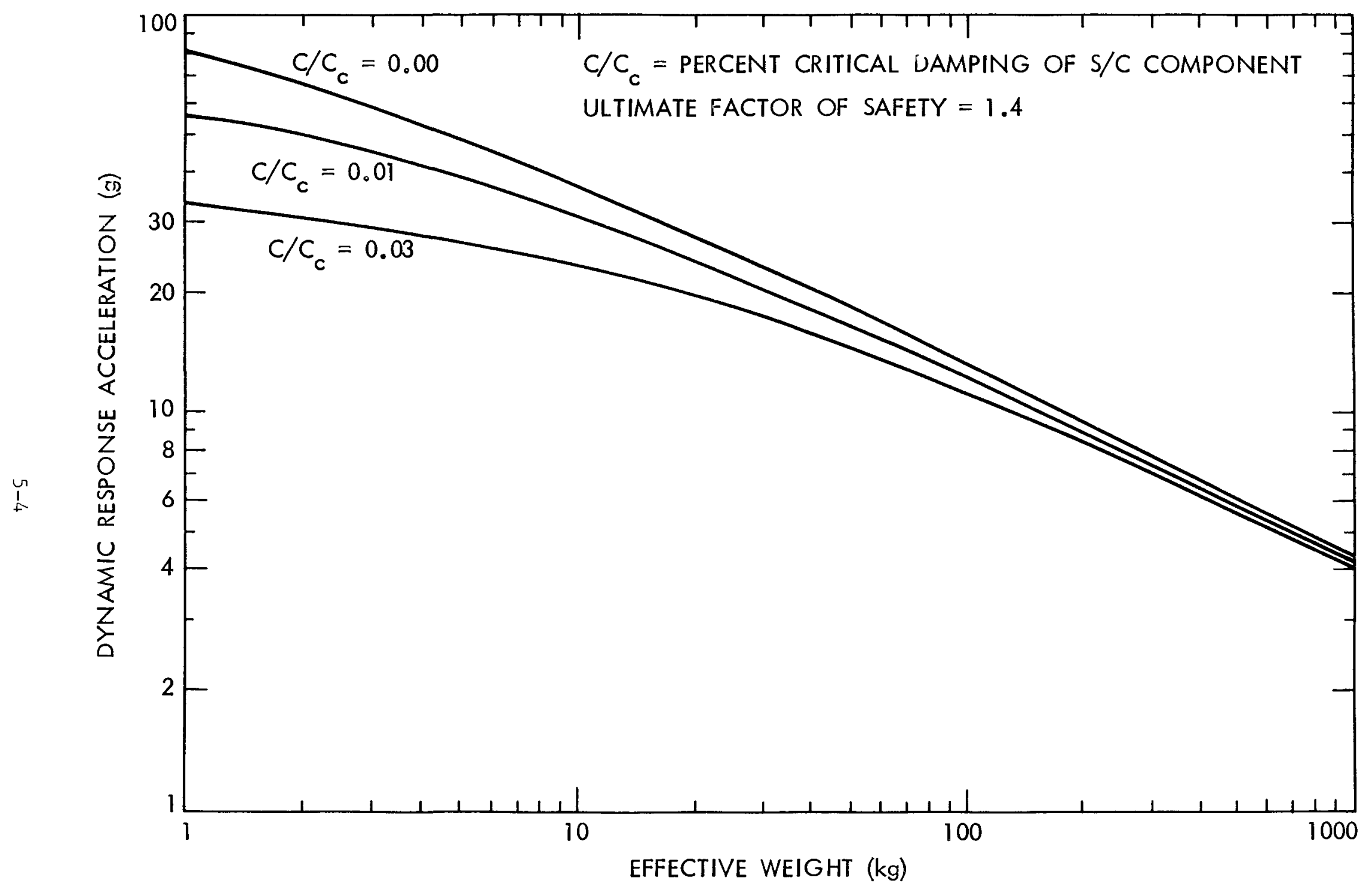

Figure 5-3. Preliminary Design Limit Loads 
JSC $07700 \mathrm{Vol}$. XIV, Attachment 1, for component masses greater than $1000 \mathrm{~kg}$. Both the curve in Figure 5-3 and the Vol. XIV data are limit loads and should be multiplied by a factor of safety of 1.4 to obtain ultimate loads. The mass of the subsystem or component being investigated and the direction of the load factor shall be chosen to produce the maximum member load. The final design loads shall be determined by a coupled transient analysis as determined by the appropriate interface working group.

The SP-100 Flight System structural model for the integrated SIS/ Payload control/structure interaction and stability analyses shall be in accordance with the SP-100/Centaur Loads Analysis and Dynamic Interface Verification Plan (TBD).

The safety factors to be used in the structural design shall be in accordance with $\mathrm{NHB} 1700.7 \mathrm{~A}$ (Kef. 4). The SP-1UU minimum factor of satety for structure for flight phases shall be 1.4 while attached to the Orbiter, and 1.25 when deployed from the Orbiter but attached to the Centaur. Pressurized structures and vessels shall have an ultimate safety factor of two, and pressure lines and fittings an ultimate safety factor of four.

\subsubsection{Thermal Interfaces}

The physical interface between the SP-100 and Centaur is described in para. 5.1.1.1. Physical contact occurs only at the attachment points and electrical interface connectors with appropriate contact conductance applied at the specific contact locations. The heat transfer mode across the 168.6in.-diameter interface is radiation. The centaur will provide an insulation blanket across this interface. Radiative properties of this blanket on the SP-100 side are TBD. Estimates of the thermal environment that the SP-100 may be exposed to during various phases of NSTS mission operations are described in para. 2.4. Thermal control constraints during launch, on-orbit operations, and Centaur-powered flight phases shall be resolved through the appropriate technical working group and controlled by the SP-1UU/Centaur mechanical ILD $(\mathrm{TBD})$.

\subsubsection{Fluid Interfaces}

There are standard fluid interfaces provided by the Centaur for RIG cooling or science instrument purge, if required.

\subsubsection{Avionics and Electrical Power Interfaces}

5.1.4.1 Electrical Power Interfaces. Power to the SP-100 from prelaunch through separation of the SP-100 from the Centaur will be distributea through the Centaur Avionics System. During prelaunch, ascent and on-orbit phases, the power to the spacecraft will be provided from SH-100 electrical ground support equipment (EGSE), Shuttle Orbiter, or Centaur/CISS (CISS: Centaur Integrated Support System) as required. The centaur and/or (ASE batteries are controlled by the Centaur avionics to assure continuous uninterrupted power to the SP-l $U$ if Orbiter power is lost. The average continuous power available to the SP-lUU 
will be 400 watts at $28+4 \mathrm{Vdc}$. Special power requirements by SP-100 shall be resolved by the appropriate technical working group and aocumented in the SP-100/Centaur Electrical ICD (TBD).

5.1.4.2 Telemetry. The NSTS will transmit continuously, in near-real time, SP-100 engineering telemetry data from launch to separation of the SFs from the Centaur. SP-IGU engineering telemetry rates during ascent, and during SP-10U/ Centaur post-deployment operations through separation of the $S \mathrm{P}-1 \mathrm{CU}$ from Centaur, is limited to $2 \mathrm{kbps}$. For $\mathrm{SP}-10 \mathrm{U}$ verification testing during on-orbit operations, data rates up to $32 \mathrm{kbps}$ can be accommodated via the MSTS $\mathrm{S}$-band; with the Ku-band system, rates up to $64 \mathrm{kbps}$ can be handled.

The block diagrams in Figures 5-4 and 5-5 show the Centaur/urbiter/ SP-100 telemetry functional interfaces.

5.1.4.3 Commands. During the attached phase when the Centaur/SP-1U0 are located in the Shuttle Orbiter cargo bay, the Shuttle Orbiter will provide the capability of transmitting serial commands to the SP-1UU via the Centaur interface. After deployment from the Urbiter, serial commands to the SP-100 cannot be provided. For the detached phase through separation of the SP-1UU from the centaur, the Centaur can provide discrete commands to the SH-1UU. The Centaur will have the capability of providing up to eight discrete commands, redundantly, to the SP-1UU at any time from launch to separation, repeatedly and in any preprogrammed sequence. Also, the capability exists to provide four additional discrete commands, redundantly, which may be programmed to be initiated at some elapsed time after SH-lUU/Centaur separation from the Shuttle Orbiter. The separation event starts the elapsed time.

$5-5$.

The command functional interfaces are presented in Figures $5-4$ and

5.1.5 Centaur Environmental Interfaces (Detached Flight)

A preliminary estimate of the Centaur boost accelerations in the thrust direction are shown in Figure 5-6. For preliminary aesign the acceleration levels shall be multiplied by a factor of 1.25 .

5.2 TRANSFER URBIT STAGE (TUS)

Figure 5-7 shows a sketch of the Transfer Orbit Stage configuration. The preliminary requirements and and capabilities described below were derived from Ref. 11 .

5.2.1 Structural/Mechanical Interfaces

5.2.1.1 Interface Locations and Attachment. The physical interface of the spacecraft with the TOS vehicle will be with the standard IUS interface shown 


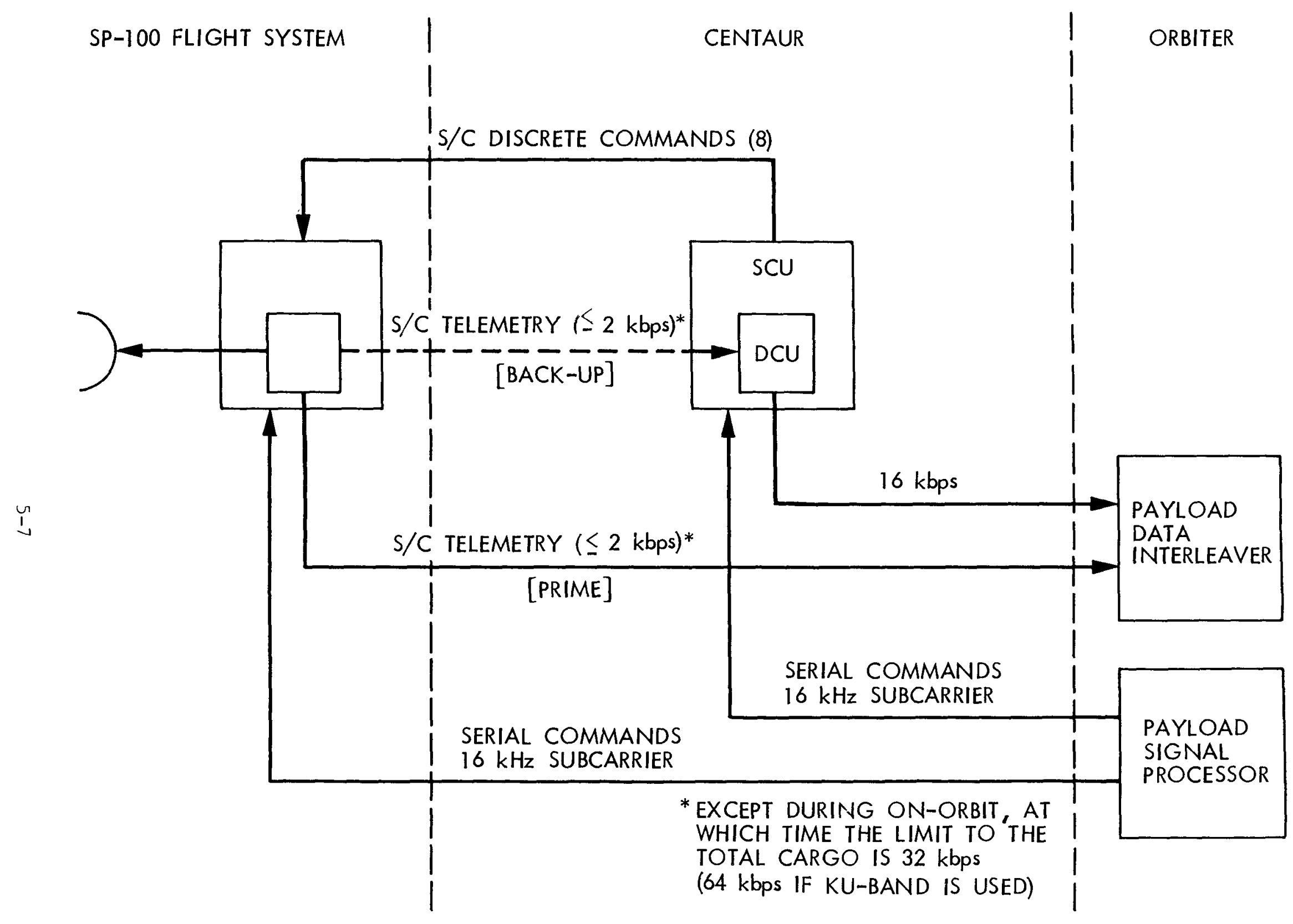
and Shuttle (Attached Phase) 


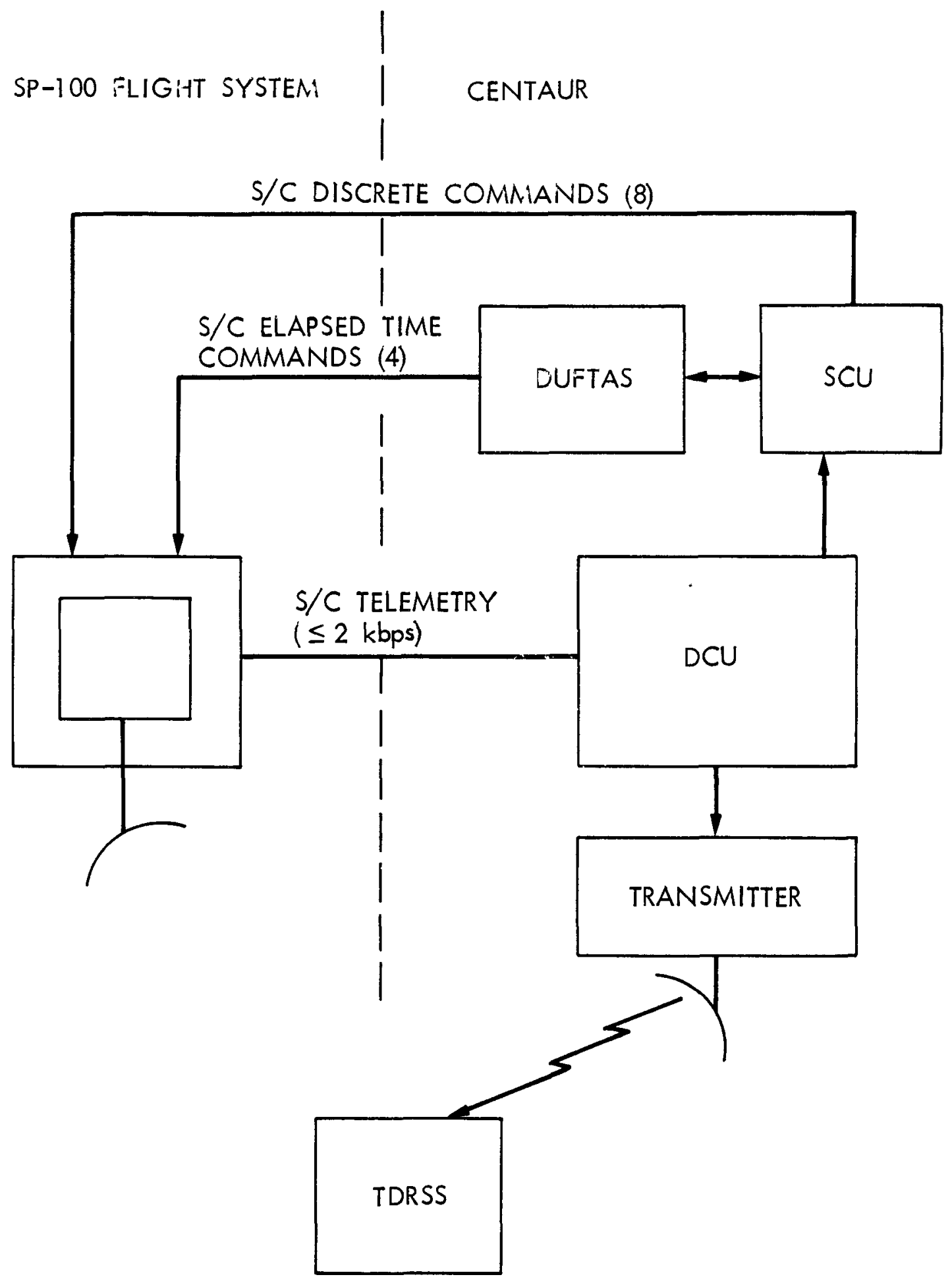

Figure 5-5. Telemetry and Command Functional Interfaces with Centaur (Detached Phase) 


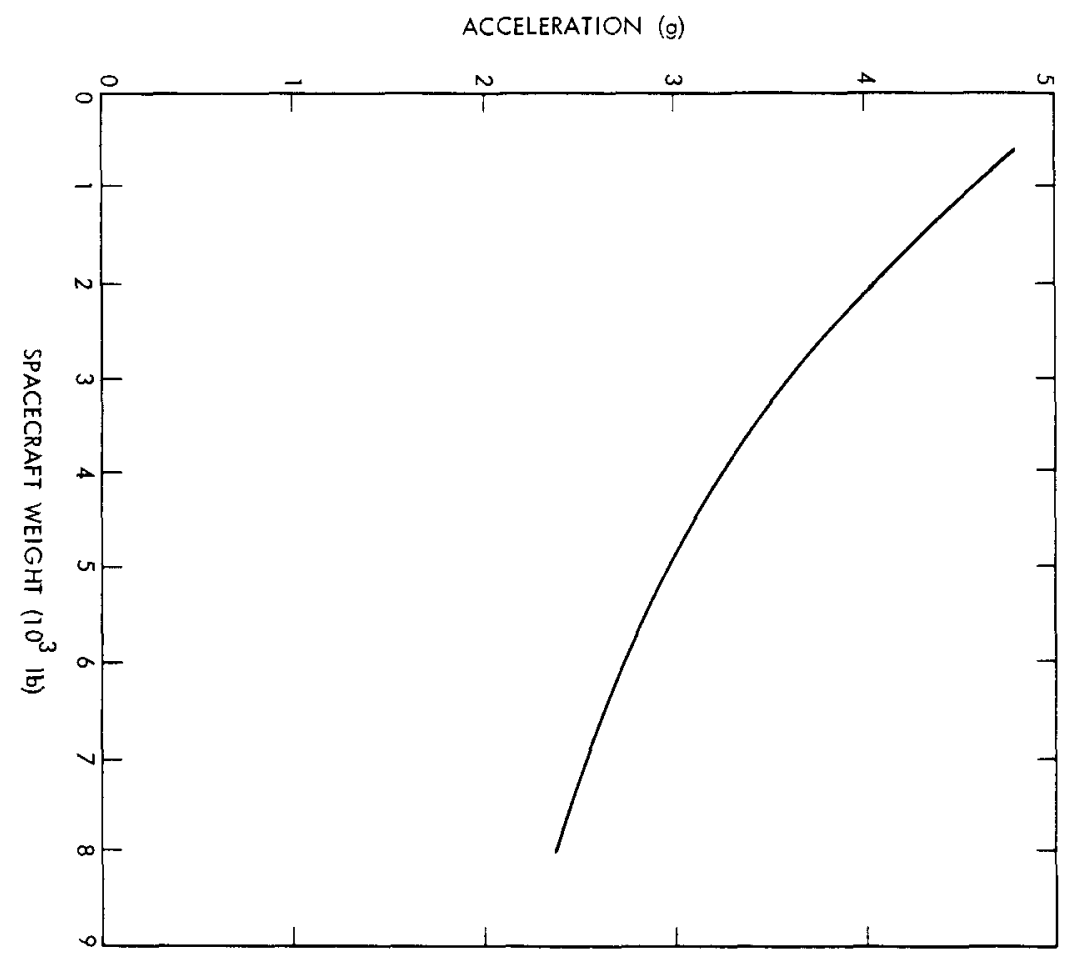

Figure 5-6. Centaur boost Acceleration

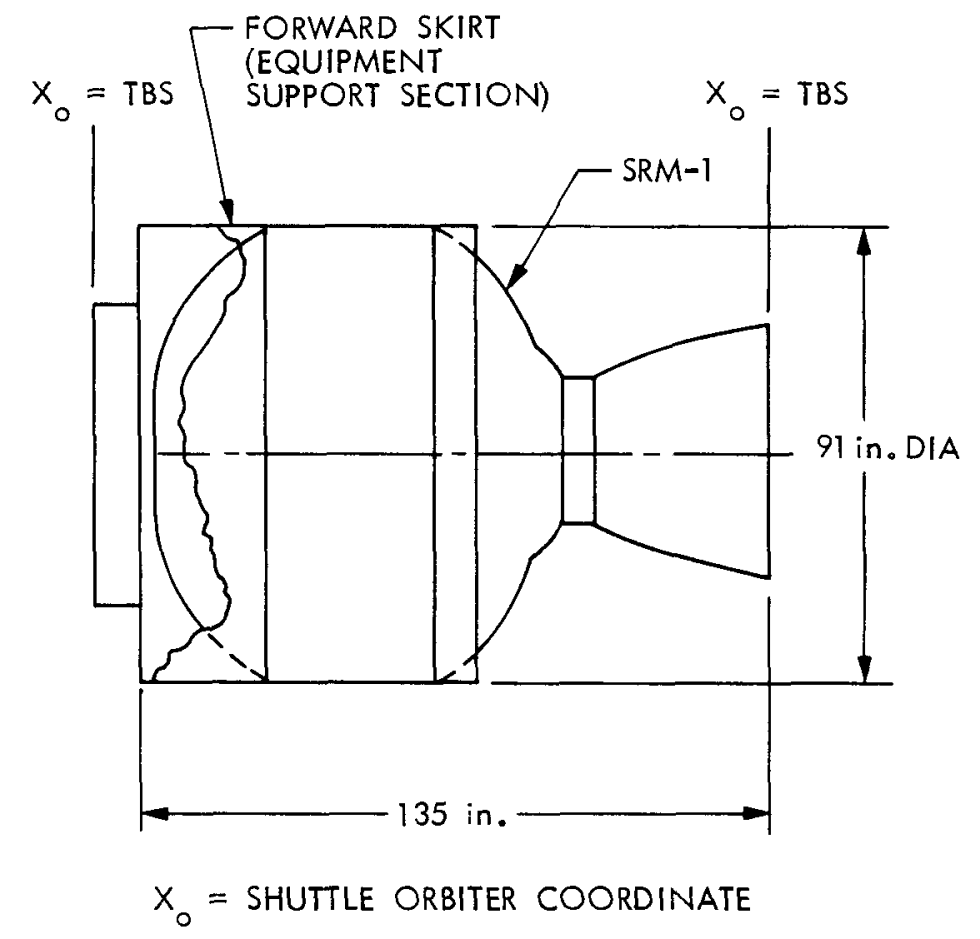

Fiqure 5-7. Iransfer Orbit Stage Confiquration 
in Figure 5- $\gamma$. A physical interface adapter, if required, shall be provided by the spacecraft to attach to the standard TUS/spacecraft interface. Fasteners shall be provided by the spacecraft.

5.2.1.2 SP-100 Separation from IOS. The TOS/SP-100 separation system, except for the separation ordnance power and signal as defined in para. 5.2.4, shall be provided by the SP-100. The separation shall be on the spacecraft side of the standard TOS/ Spacecraft attachment interface.

5.2.1.3 Coordinate Reference Axes. The relationship of coordinates between the IOS and the Orbiter shall be as shown in Figure 5-9.

5.2.1.4 Allowable Thermal and Lynamic Envelope. The maximum spacecraft envelope, including any adapter, shall be as indicated in Figure 5-10. The spacecraft thermal, dynamics and static deflections shall be contained within this envelope, beginning with installation of the mated TOS and ending with predeployment tilt-up.

5.2.1.5 Structure and Loads. The SP-1UU Flight system shall be designed to accommodate the flight of Shuttle liftoff, ascent-to-orbit, TUS-powered flight, and Shuttle abort landings. Characteristics of the Shuttle-induced environments are described in para. 1U.U of Ref. 2. The shock environment produced by TUS at the TOS/SP-100 interface, and the boost acceleration provided by the TOS to the SP-100 during detached flight, are as described in para. 5.2.5.

The factors of safety to be used in the structural designs shall be as discussed in para. 5.1.1 above.

\subsubsection{Thermal Interfaces}

Physical contact occurs at the SP-100/TOS mechanical attachment interface described in 5.2.1.1 and the electrical interface connectors described in 5.3.4, with appropriate contact conductance applied at the specific contact locations. The thermal conduction at these intertaces shall be limited to $\mathrm{TBD}$ cal/sec - ${ }^{\circ} \mathrm{C}$ ( $\mathrm{TBD} \mathrm{BTU} / \mathrm{sec}-\mathrm{O}_{\mathrm{F}}$ ). The thermal radiation interchange between TOS and the spacecraft is TBD. The TUS will provide, if required, a multilayer insulation (MLI) blanket across the interface to limit the interchange to TBV cal/sec - (OC) 2 [TBL BTU/sec - (OF)2]. The maximum penetration of the IOS thermal blanket above or below the TUS/Spacecraft interface plane, due to billowing during ascent, will not exceed TBD inches.

\subsubsection{Fluid Interfaces}

There are no standard provisions for TUS-to-spacecraft fluid interfaces. Therefore, any purge gas requirements by a spacecraft using the baseline TOS will be the spacecraft responsibility. TOS will make available as an optional kit provisions to accommodate a thermally protected science 


\section{$2-1669$}

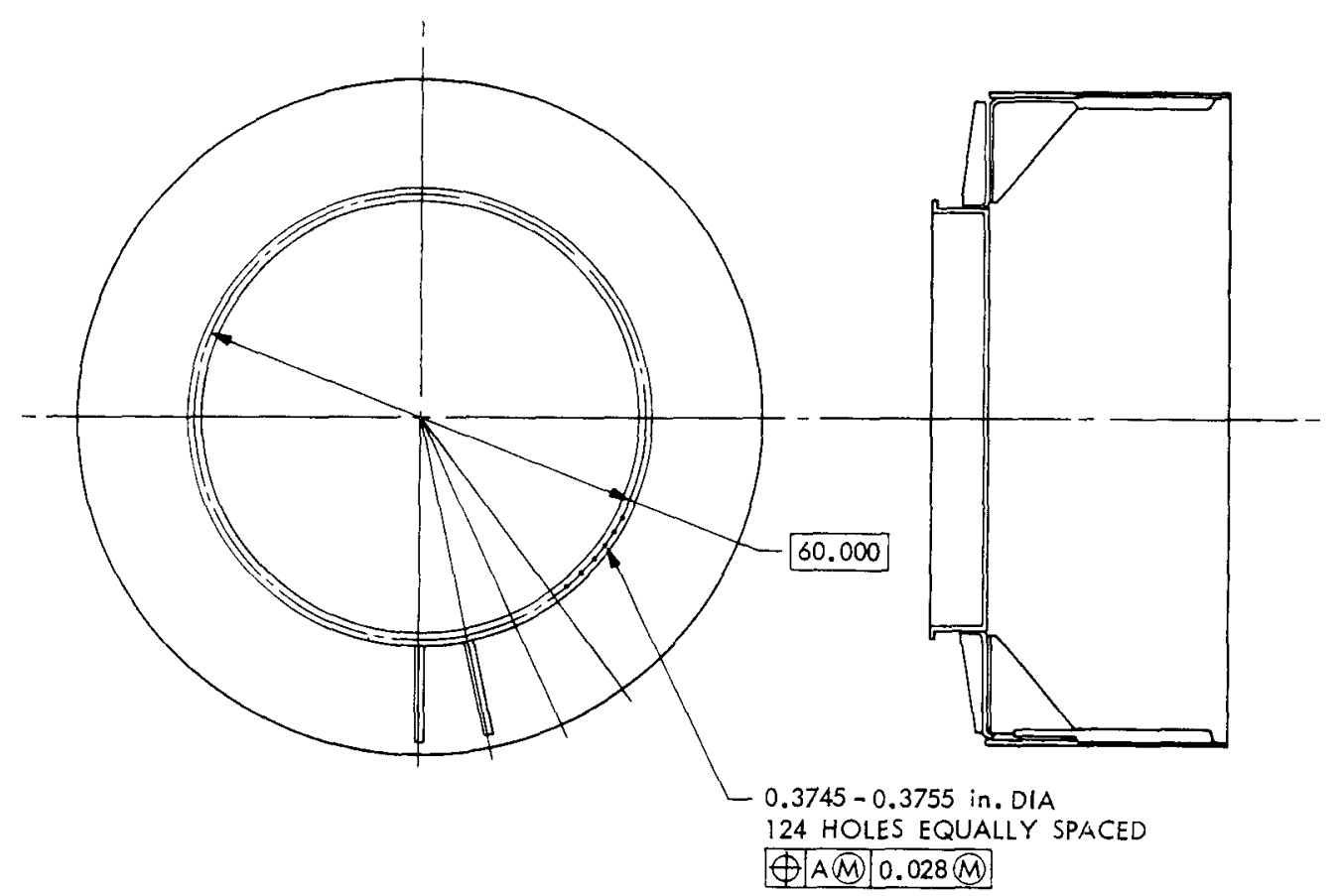

[REF: MMC ICD-575-83200]

Figure 5-8. Standard TOS/Spacecraft Interface

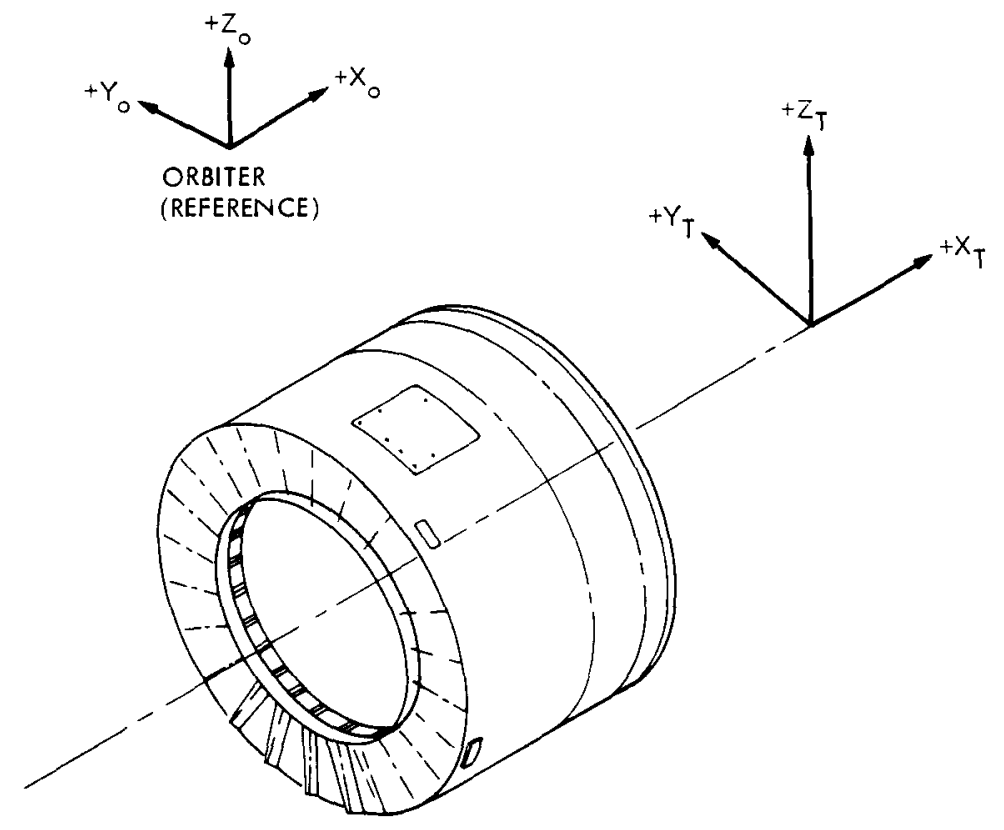

[REF: MMC ICD-STS-83200]

Figure 5-9. TOS Coordinate System 


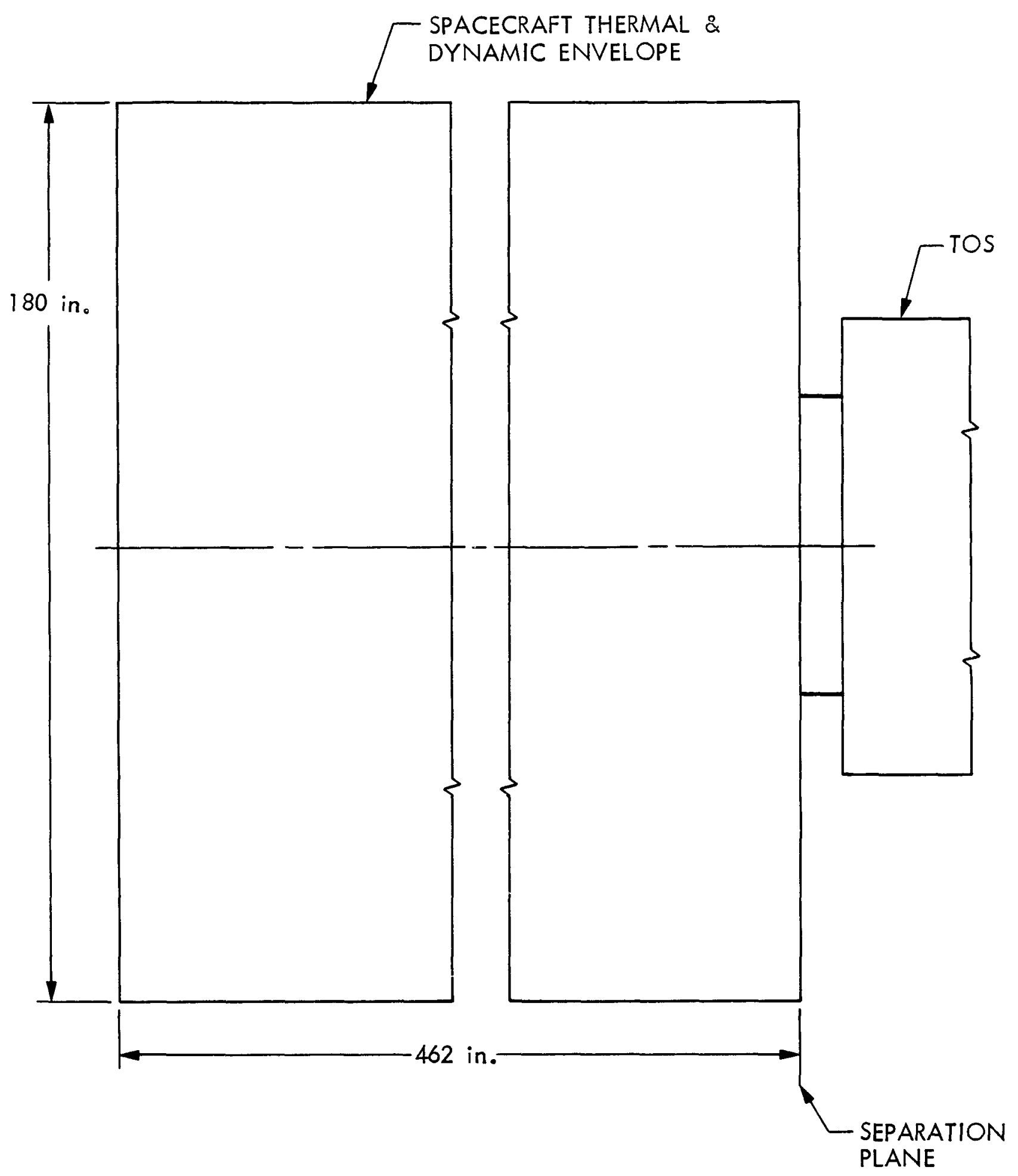

[REF: MMC ICD-STS-83200]

Figure 5-16. TOS/Spacecraft Installation in Urbiter Bay 
instrument purge line (1/4-in. OL) along the TUS, and space on the IOS ASE (cradle) for mounting a purge purification equipment package. In this case, the Orbiter would provide the purge gas.

\subsubsection{Avionics and Electrical Interfaces}

Standard TOS electrical interfaces are provided for distributing ordnance firing power, sequencing discretes, and separation indication, as described in 5.2.4.1 and 5.2.4.2 below. Available kit options could provide additional wiring and connector provisions for electric power, command and telemetry data interface connections between TOS and the spacecraft.

5.2.4.1 Electrical Connectors and Wiring. The TuS/Spacecraft electrical interface connectors will be low-force, lanyard-actuated connectors. Access for mating these connectors will be from the spacecraft side of the ToS/Spacecraft interface.

5.2.4.2 Electrical Power. The ordnance power interface consists of three sets of redundant capacitive discharge pyrotechnic firing circuits designed to fire NASA Standard Initiators (NSIs). The sequencing interface consists of four redundant discretes that are relay closures to spacecraft-furnished power. These discretes will be generated in the TOS sequencer as time-scheduled functions. Included on the TOS side of the interface is a connector wire that can be used by the spacecraft as a separation indication.

\subsubsection{TOS Detached Phase Environmental Interfaces}

5.2.5.1 Contamination. The TOS vehicle is being designed so that the main propulsion system and reaction control system (KCS) thruster exhaust will not impinge directly or be reflected upon the SP-100 Flight System during any mode of RCS thruster or main engine operation.

\subsubsection{Vibration, Shock, and Axial Accelerations. (TBD)}

\section{$5.3 \quad$ INERTIAL UPPEK STAGE}

An outline sketch of the two-stage (standard) Inertial Upper Stage (IUS) is shown in Figure 5-11. Ref. 12 provides a summary description of the IUS system. Kef. 13 defines the "generic" interface capabilities provided by the two-stage IUS, which are the standard features incorporated in all twostage IUS vehicles. Where specific spacecraft requires IUS hardware additions/ deletions, changes must be planned/programmed to assure an IUS tailored to the specific mission. Ref. 13 should be consulted for additional details about the IUS/spacecraft interfaces. 


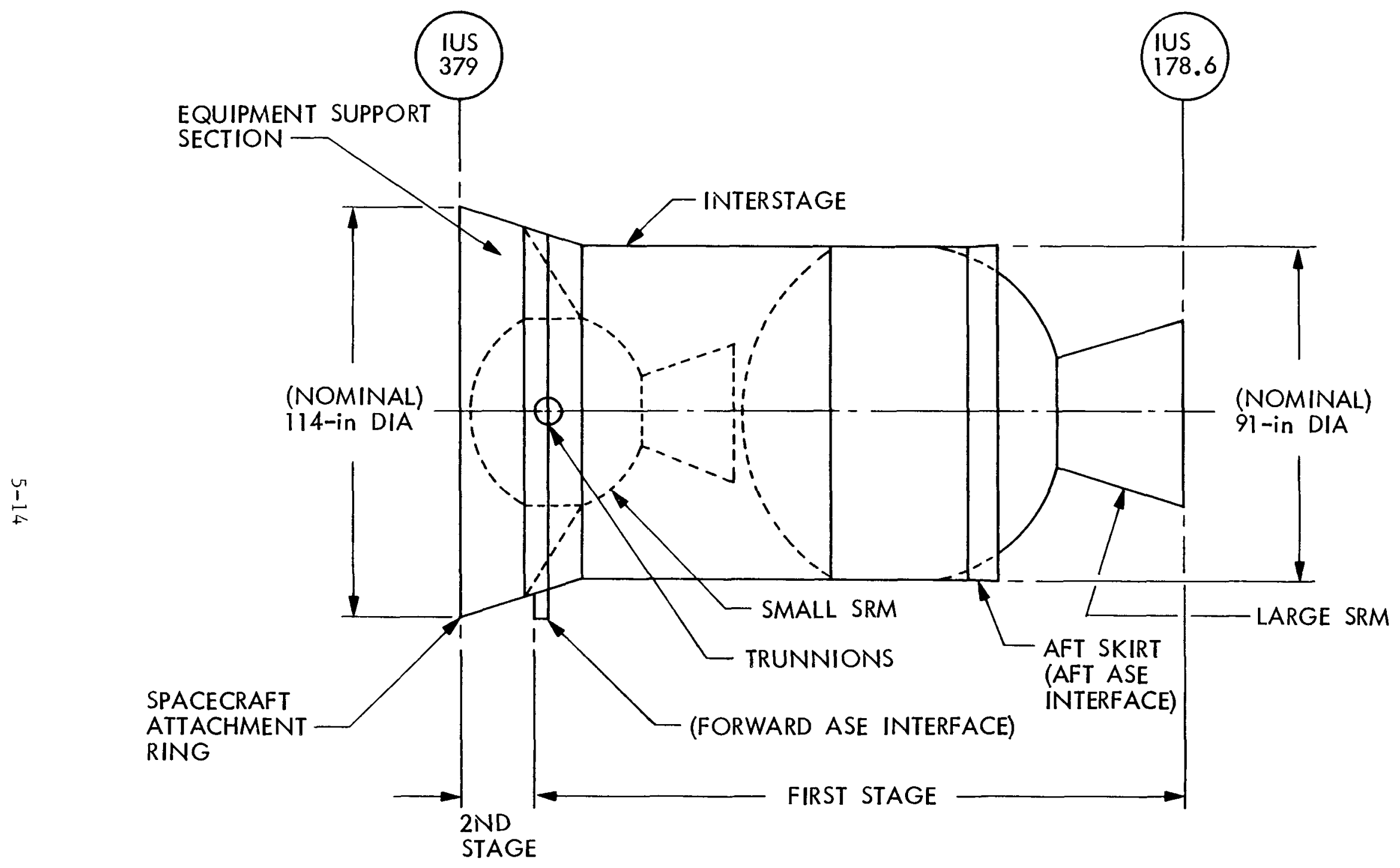

[REF: ICD-A-81200, REV. A] 


\subsubsection{Structural/Mechanical Interfaces}

5.3.1.1 Interface Locations and Attachments. The SY-lul will mechanically interface with the IUS spacecraft attachment ring at the forward end of the equipment support section. Attachment provisions are by a maximum of eight attachment points as shown in Figure 5-1\%.

All electrical connections between IUS and $S F-100$ are made through 11 screw-on bayonet-type electrical connectors mounted on a bracket on the IUs at IUS station 379. Access for mating to the connectors is from the spacecraft side of the interface plane.

The IUS provides a multilayer insulation (MLI) blanket across the spacecraft/IUS interface plane enclosed by the 111.77 -inch-diameter bolt circle. This insulation blanket will be restrained to minimize billowing during ascent and to prevent contact with spacecraft separation harciware. The maximum penetration of the blanket about the spacecraft/IUs interface plane due to billowing will not exceed Thb inches.

5.3.1.2 SP-1CU Separation from the IUS. The spacecraft separation system shall be provided by the spacecraft, except, if required, for separation ordnance power as defined in para. 5.3.4.3. The separation plane is normally displaced from the IUS/Spacecraft attachment interface by a spacecraft-provided adapter that will remain with the IUS when the spacecraft separates.

5.3.1.3 Coordinate Reference Axes. The relationship of coordinates between the IUS and the Shuttle Orbiter is shown in Figure 5-13.

5.3.1.4 Allowable Thermal and Dynamic Envelope. The maximum available SP-1UG length for an IUS/Spacecraft payload is shown in Figure 5-14.

5.3.1.5 Structure and Loads. The SP-lOU structure shall be designed to meet the flight loads of SSV liftoff, ascent to orbit, IUS flight phase, and abort landings. Characteristics of the Shuttle-induced environments to be used in structural design are described in Section 16.6 of Ref. 2. The IUS environmental interfaces are described in para. 3.3, Ref. 13. Factors of safety to be used in structural design are as described in para. 5.1.1 above. The allowable payload cg envelope is presented in Kef. 13.

\subsubsection{Thermal Interfaces}

The physical interfaces between the IUS and SP-lUU are as shown in Figure 5-12. Physical contact occurs only at the eight attachment points and electrical interface connector bracket. The insulation bracket across the area enclosed by the bolt circle is made up of aluminized kapton with polyester net spacers and an outer layer of aluminized Beta Cloth (Beta Cloth-side out). Physical properties of this insulation, and the IUS thermal analysis requirements on the spacecraft, are as described in para. 3.2.4, Kef. 13. 


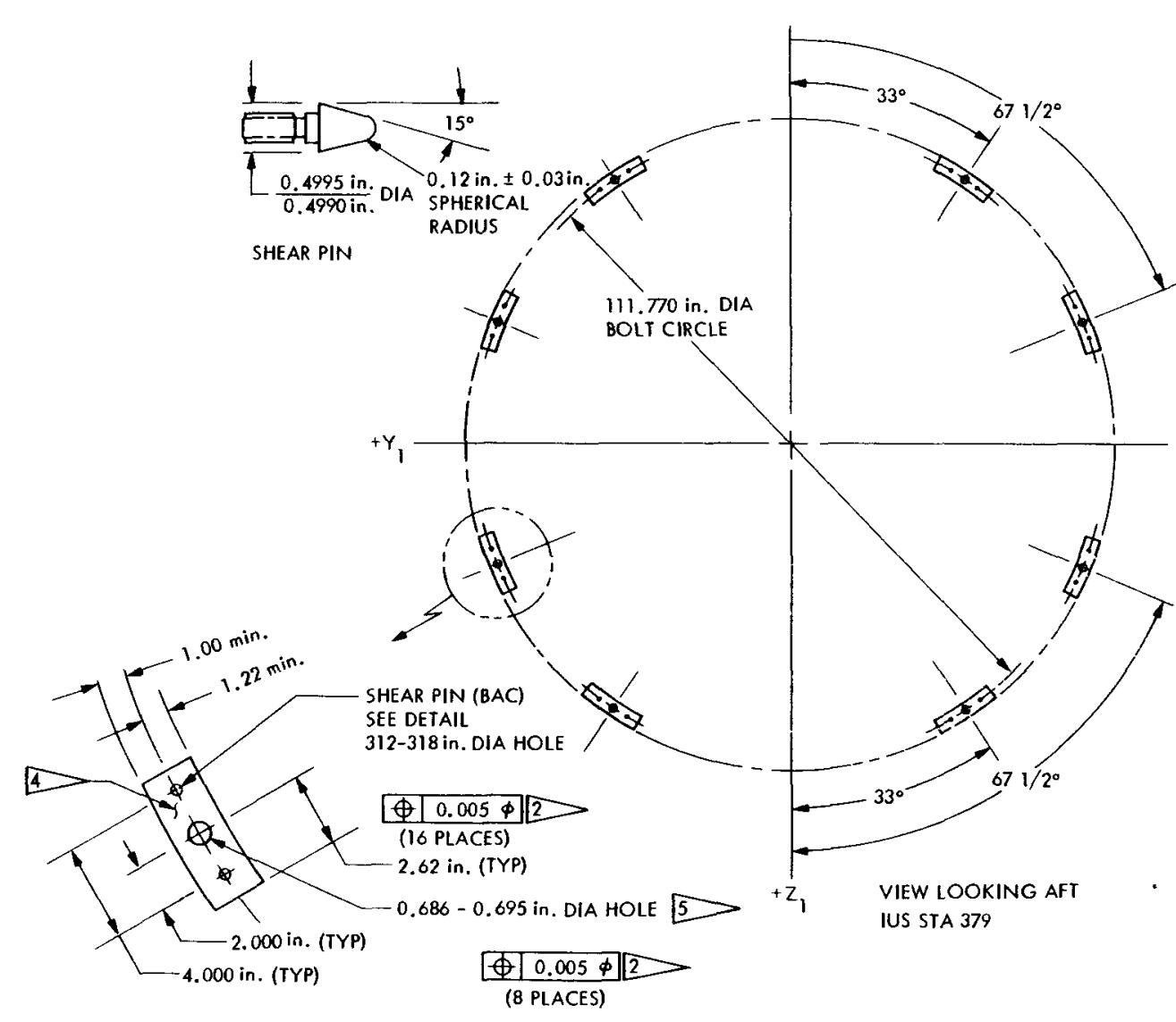

D. Deleted

2 The tRUE POSITION TOLERANCE INDICATED APPLIES TO THE TRANSFER OF NOTED HOLES FROM THE MASTER GAGE TO THE FINAL HARDWARE.

3. EQUIPMENT SHALL NOT CROSS THE IUS/SC INTERFACE MOUNTING PLANE UNLESS NOTED ON THIS DRAWING.

4. EACH IUS AND SPACECRAFT MOUNTING SURFACE SHALL BE FLAT WITHIN 0.004 INCH PER INCH. TOTAL NOT TO EXCEED 0.01O INCH MEASURED IN ALL DIRECTIONS.

ALL ATTACHED SURFACES SHALL LIE BETWEEN TWO PARALLEL PLANES WHICH ARE 0.030 INCH APART AND PERPENDICULAR TO THE IUS $X$ AXIS.

5 . PROVISIONS FOR 1.00-INCH-DIA BOLT OPTIONAL.

Figure 5-12. IUS/SC Attachment Interface 


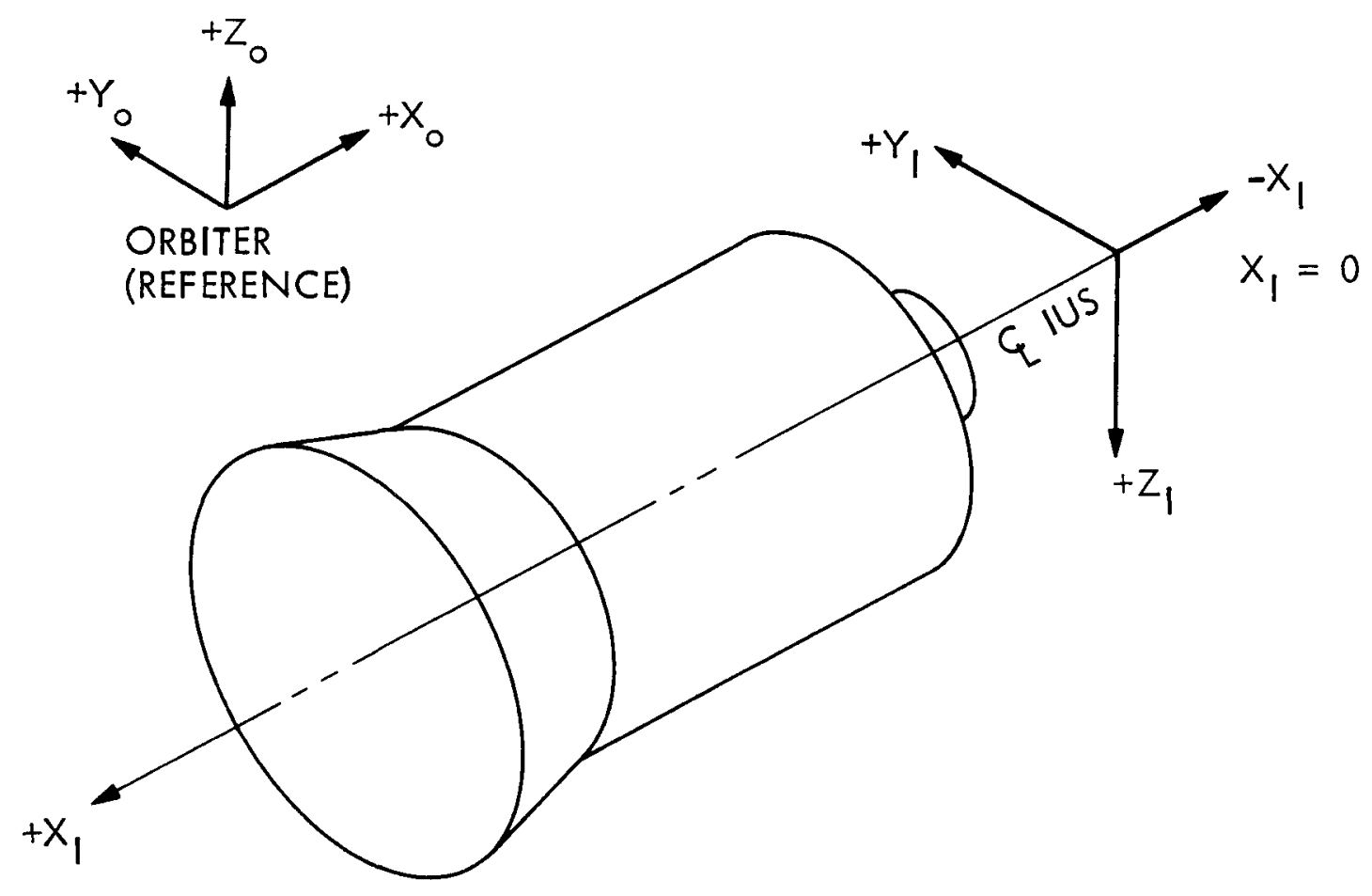

ORIGIN: STATION 0.0 IS 379.0 INCHES AFT OF THE SPACECRAFT INTERFACE PLANE. WATERLINE 0.0 AND BUTTLINE 0.0 ARE AT THE VEHICLE GEOMETRIC CENTERLINE.

$x:$ POSITIVE UP WITH ORBITER IN LAUNCH POSITION. THE $X$-AXIS IS ON THE VEHICLE GEOMETRIC CENTERLINE NORMAL TO THE FORWARD INTERFACE PLANE.

Y: POSITIVE RIGHT. (TO COMPLETE A RIGHT-HAND SYSTEM)

z: POSITIVE DOWN WITH ORBITER IN LANDED POSITION. VEHICLE CLOCK ANGLE: MEASURED POSITIVE CLOCKWISE AS VIEWED FROM THE +X END OF THE IUS VEHICLE. THE ${ }^{+} Z$-AXIS IS O CLOCK ANGLE.

[REF: ICD-A-81200, REV. A] 


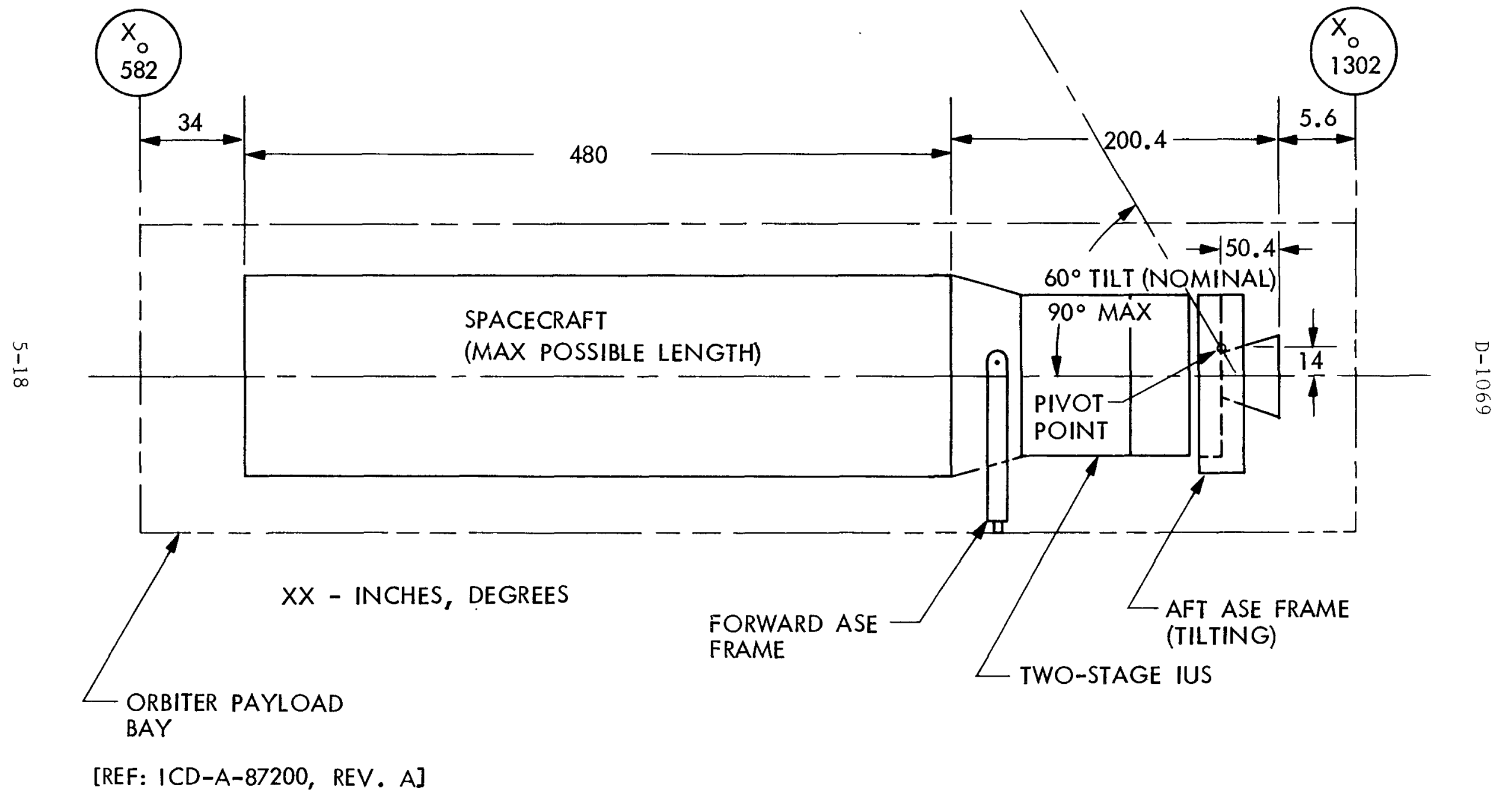

Figure 5-14. Single IUS/Spacecraft Installation 
5.3.3 Fluid Interfaces

faces.

There are no standard provisions for IUS-to-spacecraft fluid inter-

5.3.4 Avionics and Electrical Power Interfaces

5.3.4.1 Electrical Connectors and Wiring. Figure 5-15 shows the IUS system functional interfaces available to the spacecraft for distribution of electrical power, ordnance power, command discrete, telemetry data, spacecraftdedicated circuits and RF signals. Ref. 13 specifies the standard wiring and connector provisions available for interface connections between the IUS vehicle and the payload.

5.3.4.2 Electrical Power. The power interfaces with the spacecraft will be through the IUS avionics system for the launch countdown and subsequent ascent and flight phases to IUS-spacecraft separation. During the prelaunch, ascent and on-orbit phases, the power to the spacecraft will be provided from spacecraft electrical ground support equipment (EGSE), Shuttle urbiter, or IUS ASE as required. The IUS and IUS ASE batteries are also used and controlled by the IUS Avionics to assure uninterrupted power to the spacecraft in the event of loss of Urbiter power. Electrical power provided by the IUS to the IUS/ Spacecraft connector interfaces shall be at $2 \delta+4 \mathrm{Vdc}$.

5.3.4.3 Ordnance Power. The IUS shall provide and distribute ordnance power to the IUS/ Spacecraft interface for access (if required) by the spacecraft for the firing of ordnance devices in two groups of eight initiators. Details of this power are described in kef. 13.

5.3.4.4 Telemetry. The NSTS is required to transmit continuously, in nearreal time, spacecraft engineering telemetry from launch to IUS/spacecraft separation. During ascent and on-orbit operations (prior to deployment from the Orbiter) the spacecraft telemetry will be delivered to the Shuttle urbiter payload data interleaver (PDI) via IUS-provided wiring for insertion into the Orbiter operational instrumentation (UI) data stream as illustrated in Figure 5-16. During ascent, spacecraft telemetry rates are limited to $2 \mathrm{kbps}$. For on-orbit spacecraft verification testing, higher rates can be accommodated depending on whether the NSTS S-band or Ku-band is used. If the S-band is used, data rates up to $32 \mathrm{kbps}$ can be handled; with the ku-band, $64 \mathrm{kbps}$. After deployment of the SP-100/IUS, the IUS will interleave up to $2 \mathrm{kbps}$ of Spacecraft data and telemetry via TDKS $S$-band through to Spacecraft separation (see Figure 5-17).

5.3.4.5 Commands. Serial commands for the SP-luU from launch through to deployment from the Shuttle Orbiter, are processed via TDRS, the Shuttle Orbiter PSP, through the IUS, to the spacecraft (see Fig. 5-16). After deployment, serial commands to the spacecraft are not possible because the Ils 


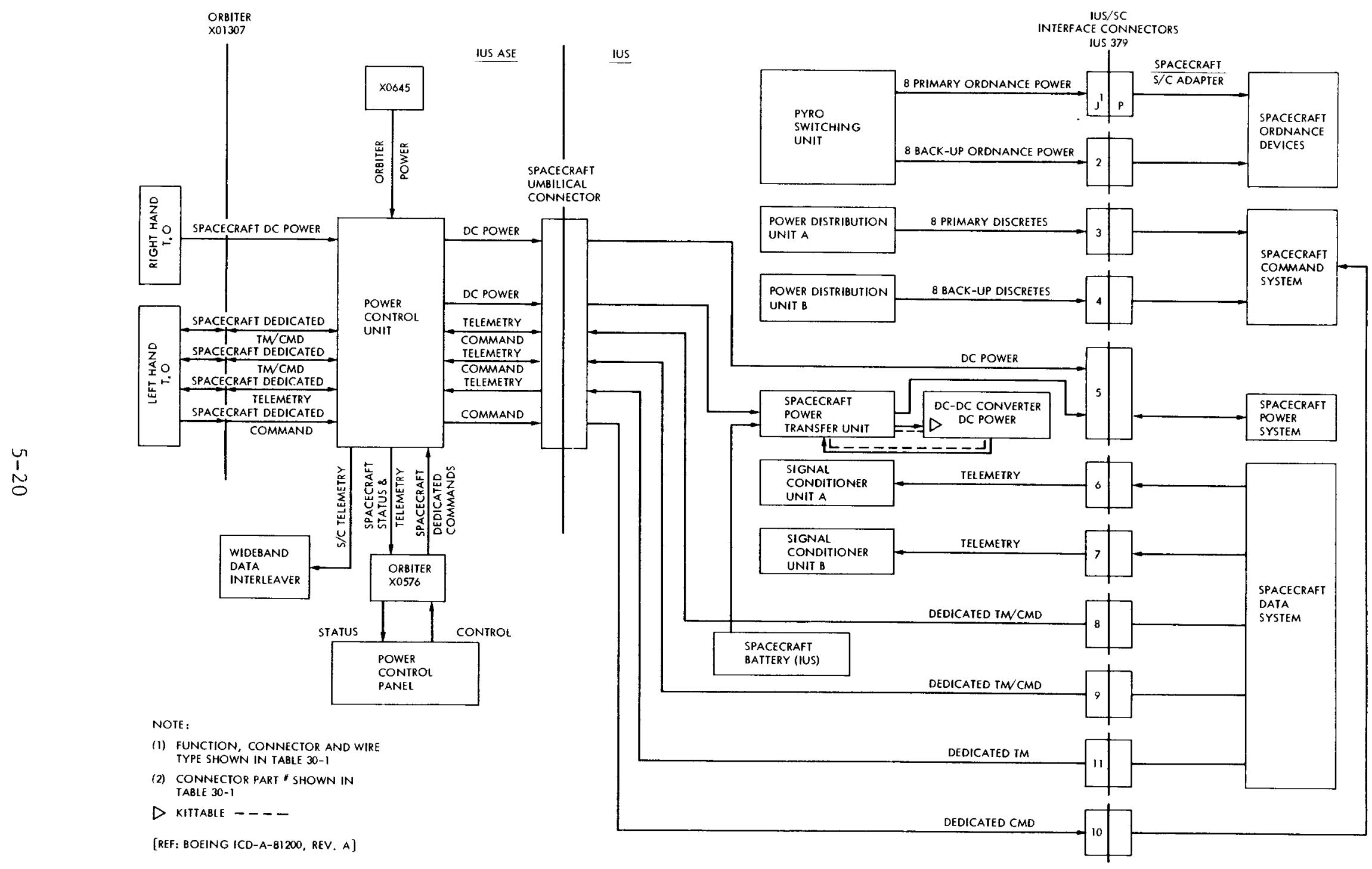




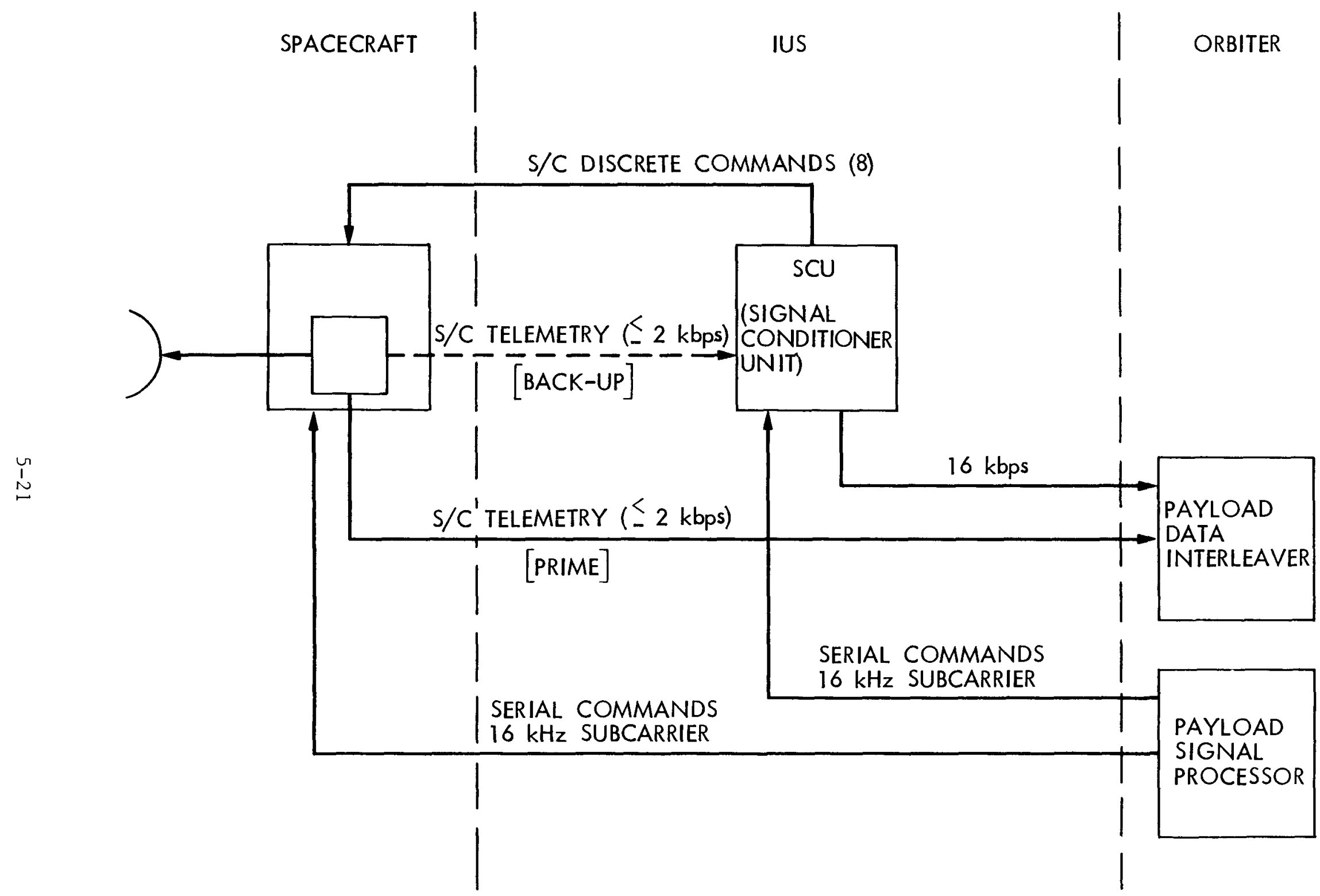

Figure 5-16. Telemetry and Command Functional Interefaces with IUS and Shuttle (Attached Phase) 
system does not provide such an interface to the spacecraft. For the detached phase through Spacecraft-IUS separation, the IUS will have a ground-initiated discrete command link via the space-ground link system (SGLS) capability. The IUS will have the capability of sending to the spacecratt up to eight redundant discrete commands at any time from launch to separation, repeatedly, and in any preprogrammed sequence. Figure $b-17$ shows the command functional interfaces during the detached phase.

5.3.5 Environmental Interfaces. The environmental conditions at the IUS/ Spacecraft interfaces are presented in para. 3.3, Ref. 13. 


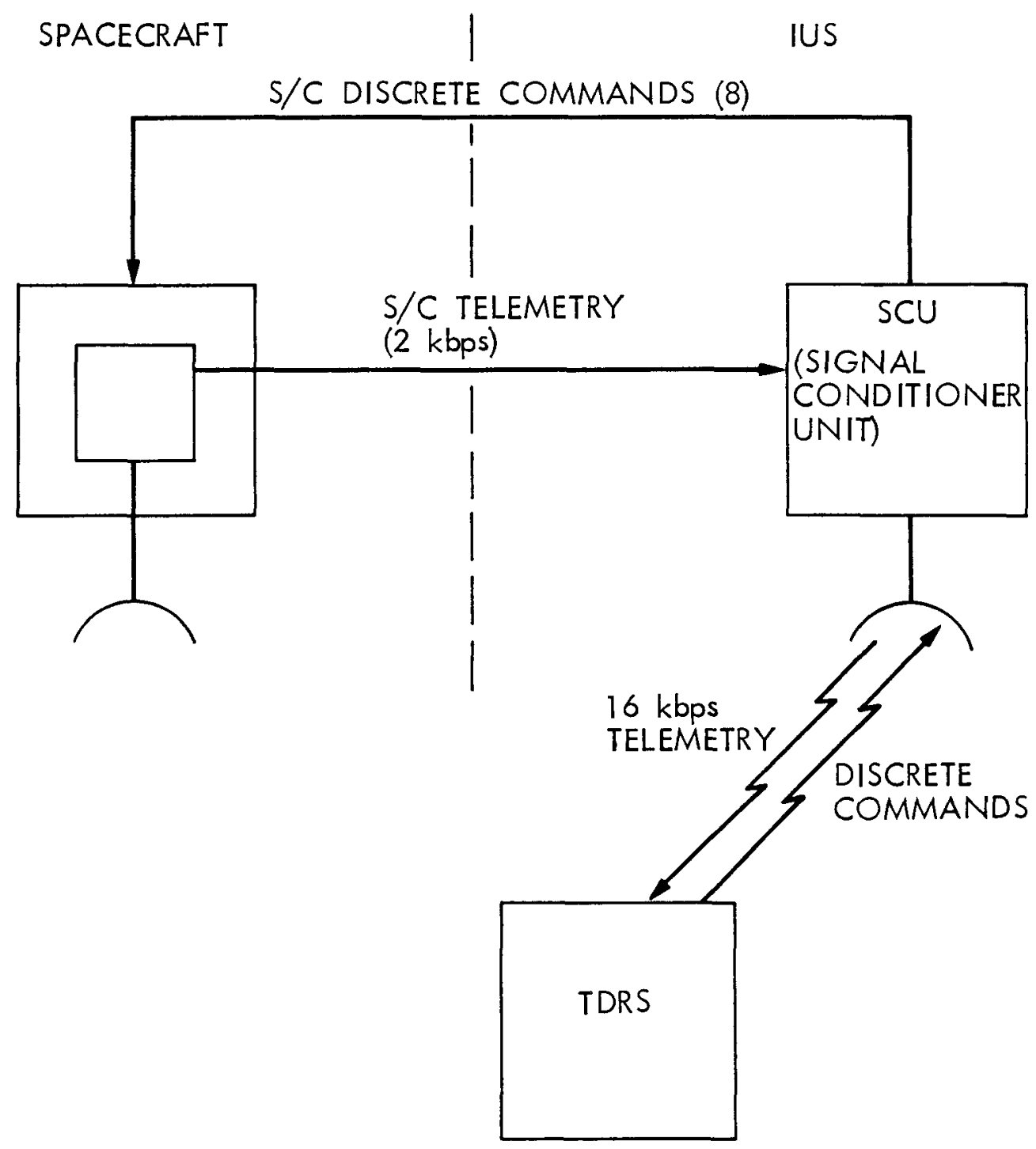

Figure 5-17. Telemetry and Command functional Interfaces with Ius (Letached Phase) 


\section{SECTION 6}

\section{PAYLOAD/NSTS INTERFACE VERIFICATION}

The National Aeronautics and Space Administration (NASA), for purposes of maintaining personnel safety and Orbiter integrity, has established minimum payload requirements for verifying the payload-to-shuttle physical and functional interfaces. Ref. 14 establishes the basic requirements for the verification. The user is responsible for verifying compatibility of the payload interfaces with the applicable interface agreements. All payload physical and functional interface compliance is expected to be accomplished prior to installation of the payload in the Orbiter cargo bay. NASA is responsible for verifying Cargo Integration Test Equipment (CITE) and orbiter payload-dependent interface compliance before payload installation. 
SECIION 7

KEFEKENCE LCCLMENIS

(1) JSC 07700

Vol. XIV

(2) JSC 07700 Vol. XIV, Att 1 (ICL 2-19001)

(3) K-STSM-14.1

(4) $\mathrm{NHB} 1706.7 \mathrm{~A}$

(5) $\mathrm{KHB} 1700.7$

(6) JSC 14363

(7) JSC 14029

(8) JSC 13830

(4) CGTD-3

(GDC Rept)

(10) GDC-SSC-83-010 (GDC Rept)

(11) ICD-STS-83200 (MMC Doc.)

(12) L $250-10652-1$ (Boeing Loc.)

(13) ICD-A-81200 (Boeing Doc.)

(14) JSC 14046
"Space Shuttle System Payload Accommodations"

"Shuttle Orbiter/Cargo Standard Interfaces"

"Launch Site Accommodations handbook for STS Payloads"

"Safety Policy and Requirements for Payloads Using the Space Transportation System"

"Space Transportation System Payload Ground Safety handbook"

"Space Transportation System Shuttle/Yayload Integration Activities Plan"

"Shuttle/Payload Standard Integration Plan for Deployable-Type Payloads"

"Implementation Procedure for STS Payloads system Safety Requirements"

"Centaur G Technical Description (February 1983)"

"Centaur G" Technical Description (January 23, 1984)"

"Interface Control Document Transfer Orbit Stage system to Spacecraft (Generic) (Preliminary)"

"Inertial upper Stage User's Guide"

"lUS/Spacecraft ICD Parametric Interface Kequirements STS/Two-Stage IUS-Generic"

"Payload Interface Verification Requirements"

IGDC: General Lynamics Corp.

MMC: Martin Marietta Corp.J 
SP-100 PROGRAM OFFICE

LCDR William E. Wright, Director

Delbert F. Bunch, Deputy Director for Nuclear Technology

DARPA

Judith H. Ambrus, Deputy Director for Aerospace Technology

DOE HQ

NASA HQ

\section{SP-10Q PROJECT OFFICE}

Vincent C. Truscello, Project Manager

Herbert S. Davis, Assistant Manager

John E. Hanson, Deputy Manager for Nuclear Technology

Jack F. Mondt, Deputy Manager for Aerospace Technology

James R. French, System Definition Manager

Richard A. Wallace, Mission Analysis and Requirements Manager

KIrk G. Gerbracht, AdmInstration and Operations Manager

R. Joseph Sovle, Manager, SP-100 Office

$J P L$

JPL

Los Alamos

JPL

JPL

$J P L$

JPL

LeRC

CIVIL MISSIONS ADVISORY GROUP

PROJECT REV IEW BOARD

SAFETY ADY ISORY OOMMITITEE

\section{AIR FORCE}

Len Caveny

Lt. Jason Folg

Lt. Efren Fornoles

Lt. Steven Hoeser

Lt. Col. James Leo

Capt. David Perkins

Jim Reams

Col. Frank J. Redd
ARGONNE NATIONAL LABORATORY

Bolling AFB

AF/RPL

$\mathrm{KIr}$ I and AFB

Space Division

$\mathrm{KI} r+\mathrm{l}$ and AFB

AF/RPL

Wright-Patterson AFB

$\mathrm{Kir}$ tland AFB
BROOKHAYEN NAT IONAL LABORATORY

Herb Kouts

\section{DEPARTMENI OF ENERGY}

Dyer Kenney

Ehsan Khan

Stephen Lanes

Lt. Col. Robert Smith

Walter Von FIue

Earl Wahlquist

DOE/HQ

DOE/HQ

DOE/HQ

DOE/HQ

DOE/SAN

DOE/HQ

HEDL.

INEL

C. M. Cox

John A. Dearlen 
JOHNSON SPACE CENTER

WIII ElIIS

J. Gary Rank in

LANGLEY RESEARCH CENTEB

Ray Hook

\section{LEWIS RESEARCH CENTER}

Henry Slone

Ronald Thomas

LOS ALAMOS NATIONAL LABORATORY

Jay Boudreau

Kaye D. Lathrop

NASA

Wayne Hudson

Jerome P. MullIIn

Frederlck Bowen Jr.

NAYY

Cdr. Larry Burgess

LCDR WIIII am Mohr

Blll Schmidt

Jim Severance

OAK RIDGE NATIONAL LABORATORY

WII Ilam Harms

SANDIA NATIONAL LABORATORY

Lou Cropp
JPL

Internal Distribution

\section{LAWRENCE LIVERMORE NATIONAL} LABORATQRY

Carl Walter
Resident offlce, KIrtland AFB

Headquarters

Resident Offlce, JPL
NAVELEX
NAVELEX
Offlce of Naval Research
Naval Research Laboratory 